Research Article

\title{
Spatiotemporal Variability and Trends in Extreme Temperature Events in Finland over the Recent Decades: Influence of Northern Hemisphere Teleconnection Patterns
}

\author{
Masoud Irannezhad (D), ${ }^{1,2}$ Hamid Moradkhani, ${ }^{3}$ and Bjørn Kløve \\ ${ }^{1}$ Water Resources and Environmental Engineering Research Unit, Faculty of Technology, University of Oulu, 90014 Oulu, Finland \\ ${ }^{2}$ School of Environmental Science and Engineering, Southern University of Science and Technology, Shenzhen 518055, China \\ ${ }^{3}$ Center for Complex Hydrosystems Research, Department of Civil, Construction and Environmental Engineering, \\ University of Alabama, Tuscaloosa, AL 35487, USA
}

Correspondence should be addressed to Masoud Irannezhad; masoud.irannezhad@oulu.fi

Received 21 February 2018; Accepted 15 July 2018; Published 19 August 2018

Academic Editor: Jorge E. Gonzalez

Copyright ( $\odot 2018$ Masoud Irannezhad et al. This is an open access article distributed under the Creative Commons Attribution License, which permits unrestricted use, distribution, and reproduction in any medium, provided the original work is properly cited.

\begin{abstract}
Fifteen temperature indices recommended by the ETCCDI (Expert Team on Climate Change Detection and Indices) were applied to evaluate spatiotemporal variability and trends in annual intensity, frequency, and duration of extreme temperature statistics in Finland during 1961-2011. Statistically significant relationships between these high-resolution (10 km) temperature indices and seven influential Northern Hemisphere teleconnection patterns (NHTPs) for the interannual climate variability were also identified. During the study period (1961-2011), warming trends in extreme temperatures were generally manifested by statistically significant increases in cold temperature extremes rather than in the warm temperature extremes. As expected, warm days and nights became more frequent, while fewer cold days and nights occurred. The frequency of frost and icing days also decreased. Finland experienced more (less) frequent warm (cold) temperature extremes over the past few decades. Interestingly, significant lengthening in cold spells was observed over the upper part of northern Finland, while no clear changes are found in warm spells. Interannual variations in the temperature indices were significantly associated with a number of NHTPs. In general, warm temperature extremes show significant correlations with the East Atlantic and the Scandinavia patterns and cold temperature extremes with the Arctic Oscillation and the North Atlantic Oscillation patterns.
\end{abstract}

\section{Introduction}

In recent decades, changes in climatic extremes have received considerable attention in international communities due to potential effects of floods, droughts, hurricanes, severe cyclonic storms, heat waves, and cold spells (e.g., [1-5]). Previous studies showed that changes in extreme temperatures are consistent with the climate warming at the global scale [6-8]. However, the intensity and spatial pattern of such changes are different around the world (e.g., $[9,10])$. Hence, updated and systematic analysis of changes in the past extreme temperatures at the country scale plays a key role in defining national climate change adaptation strategies.

The most recent global analysis of trends in extreme temperatures shows decreases (increases) in cold (warm) extreme indices over majority of regions since 1900 (e.g., [7]). Similarly, Alexander et al. [6] reported that the annual occurrence of cold (warm) nights has decreased (increased) over $70 \%$ of the global land area during 19512003. For Europe, increases in warm days and nights, while decreases in cold days and nights, have also been determined for the last 50 years [11]. A recent analysis of trend detection in European extreme temperatures [2] confirms more warm days and nights as well as fewer cold days and nights over time during the 20th century. They also concluded increases (decreases) in the intensity and frequency of high(low-) temperature extreme events. Besides, there has been a growing interest in identifying spatiotemporal changes in extreme temperatures at the country scale (e.g., [12-14]). For Finland, however, only few studies have investigated changes in some extreme temperature indices, all focusing on several important meteorological stations 
(e.g., $[2,9,15])$. Hence, a comprehensive evaluation of fine resolution spatial patterns of variability and trends in extreme temperatures over Finland is well motivated.

Atmospheric circulation is one of the key physical processes causing the variability and changes in extreme temperatures [16] and mainly follows a number of preferred modes [17]. Such atmospheric circulation modes are generally described by teleconnection patterns (e.g., Arctic Oscillation, AO), which are defined as persistent, recurrent, and large-scale modes of atmospheric pressure anomalies. The intensity of teleconnection patterns over a particular geographical area during a specific period of the year is often expressed by numerical indices of well-known atmospheric circulation modes. Previous studies have reported most influential teleconnection patterns and their connections to surface air temperature (SAT) variability on regional, national, and global scales (e.g., [18-21]). A number of studies have particularly focused on links between changes in extreme temperatures and teleconnection patterns in different parts of the world (e.g., [22-24]).

In a previous study, Irannezhad et al. [25] focused only on long-term variations and trends in annual, seasonal, and monthly mean temperatures in Finland and their connections to different Northern Hemisphere teleconnection patterns (NHTPs). However, the present study aims at characterizing the fine resolution spatial variability and trends in extreme temperatures in Finland during 1961-2011 and improving our knowledge on the roles of NHTPs in controlling such changes. Specific objectives of the present study are to (1) determine trends in a set of extreme temperature indices; (2) evaluate spatial variations and changes in these indices throughout the country; and (3) explore relationships between the temperature indices and a number of well-established NHTPs.

\section{Materials and Methods}

2.1. Study Area and Data Description. Finland is a northern European country, extended $\sim 1320 \mathrm{~km}$ in the south-north direction between 60 and $70^{\circ} \mathrm{N}$ across the northwest of the Eurasian continent, close to the northern part of the Atlantic Ocean (Figure 1). The Arctic Ocean, the Atlantic Ocean, the Baltic Sea, the Scandinavian mountain range, latitudinal gradients, and continental Eurasia are the most important geographical factors influencing climate conditions over Finland. Temperature in Finland is generally moderate compared with the other geographical areas at the similar latitudes [26] and naturally decreases from south to north. The Köppen-Geiger climate classification system categorizes Finland as lying in the temperate of boreal zone, with no dry season (Df) [27].

For this study, daily minimum and maximum SAT time series spatially interpolated onto 3322 regular grid $\left(10^{*} 10 \mathrm{~km}^{2}\right)$ points across Finland for the years 1961-2011 (Figure 1(c)) were obtained from PaITuli-Spatial Data for Research and Teaching at the CS-IT centre for Science Ltd. website: http:// www.csc.fi/english. The Finnish Meteorological Institute (FMI) used daily minimum and maximum SAT measurements at 100-200 meteorological stations properly uniformly scattered throughout Finland (Figure 1(d)) as input to a spatial model [28] developed based on the kriging approach [29] to generate the Finnish daily gridded SAT datasets. As external forcing factors, the spatial model took into account the geographical coordinates, land elevation, the percentage of sea, and lakes at each grid cell $[28,30]$. The effects of environmental changes (including urbanisation) on actual SAT records in densely populated areas (typically located in southern Finland) were also eliminated during the producing of gridded datasets $[31,32]$. Interannual variations in the number of SAT measurement stations used by the FMI for creating the gridded minimum and maximum daily SAT time series for the period 1961-2011 are shown in Figure 1(e). The accuracy and homogeneity of the gridded daily minimum and maximum SAT data generated were qualified during the establishment of the PaITuli database. For more details of the gridding, see Venäläinen et al. [33]. The gridded time series of the PaiTuli database have previously been applied in some studies, for example, Tietäväinen et al. [30], Aalto et al. [34], Irannezhad and Kløve [35], and Gao et al. [36].

The World Meteorological Organization (WMO) Expert Team on Climate Change Detection and Indices (ETCCDI) recommends a suite of indices derived from daily SAT for evaluation of changes in extreme temperature regimes (for the complete list and detailed descriptions of the extreme temperature indices, please check the ETCCDI webpage http:// etccdi.pacificclimate.org/list_27_indices.shtml). Zhang et al. [37] also gives a review on such indices for detecting changes in extreme daily temperatures. The extreme events defined by the ETCCDI generally occur several times through a season or year. This yields more robust statistical features than other measures of extremes, which are far enough into the tails of distribution and may not be seen in quite some years [6]. Application of such predefined extreme temperature indices also allows comparability between observational and modelled SAT across different parts of the world [5]. Thus, this study uses fifteen extreme temperature indices (Table 1) recommended by the ETCCDI, with the base period of 1961-2011. Prior to calculating these fifteen indices at national scale, maximum (minimum) daily temperatures nationwide over Finland were computed as the average values of daily maximum (minimum) temperature at all 3322 grids across the country for each day throughout the period 1961-2011.

For describing the modes of atmospheric circulations, this study considers seven influential teleconnection patterns for climate variability in the Northern Hemisphere based on previous studies. These include the North Atlantic Oscillation (NAO), the Arctic Oscillation (AO), the East Atlantic (EA), the West Pacific (WP), the East Atlantic/West Russia (EA/WR), the Scandinavia (SCA), and the Polar/Eurasian (POL) patterns. The key characteristics of these seven NHTPs are summarized in Table 2. At the National Oceanic and Atmospheric Administration (NOAA) of the US, the Climate Prediction Centre (CPC) calculates standardized monthly values of these NHTPs since 1950 (available online at: http://www.cpc.ncep.noaa.gov/data/teledoc/telecontents. shtml). Corresponding to different extreme temperature indices, the present study calculates winter (Dec-Feb), summer (Jun-Aug), and annual (Jan-Dec) ACPs for the years between 1961 and 2011 as the mean of their standardized monthly values (Table 2). 


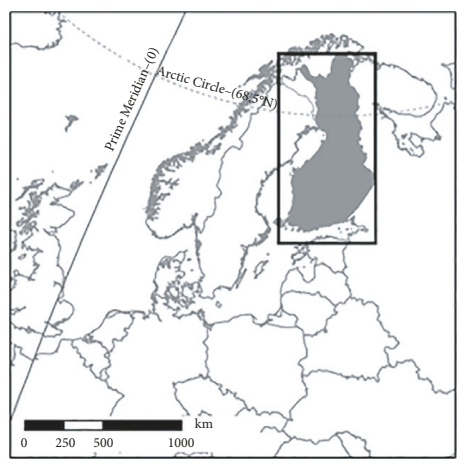

(a)

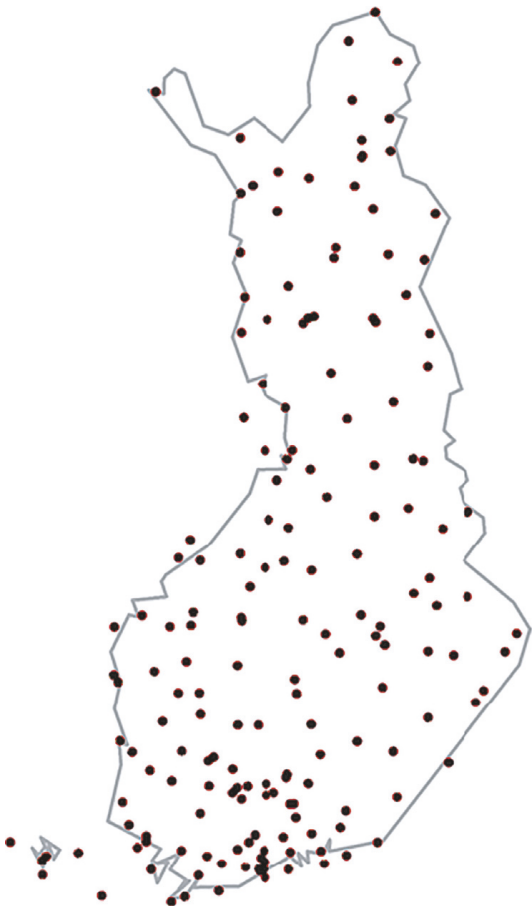

(d)

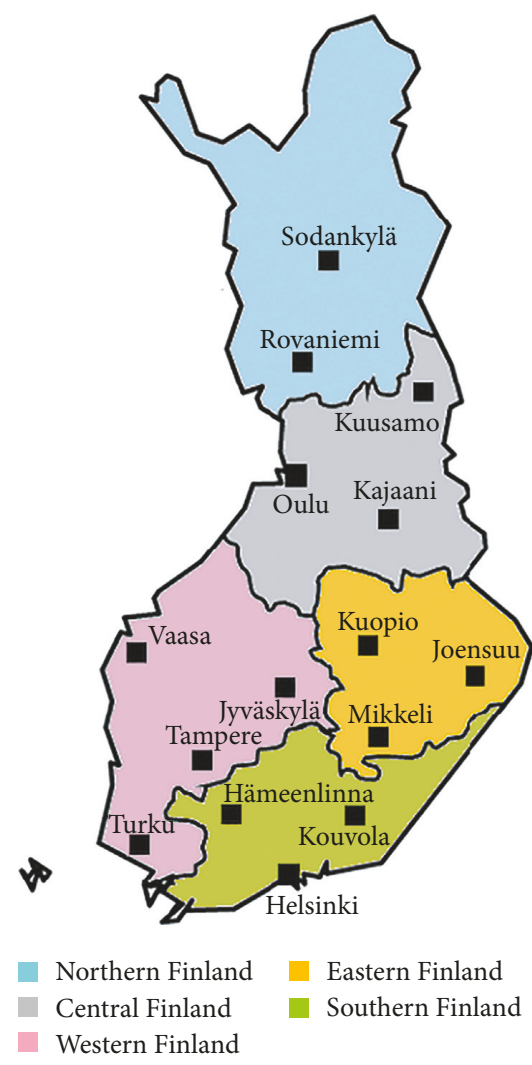

(b)

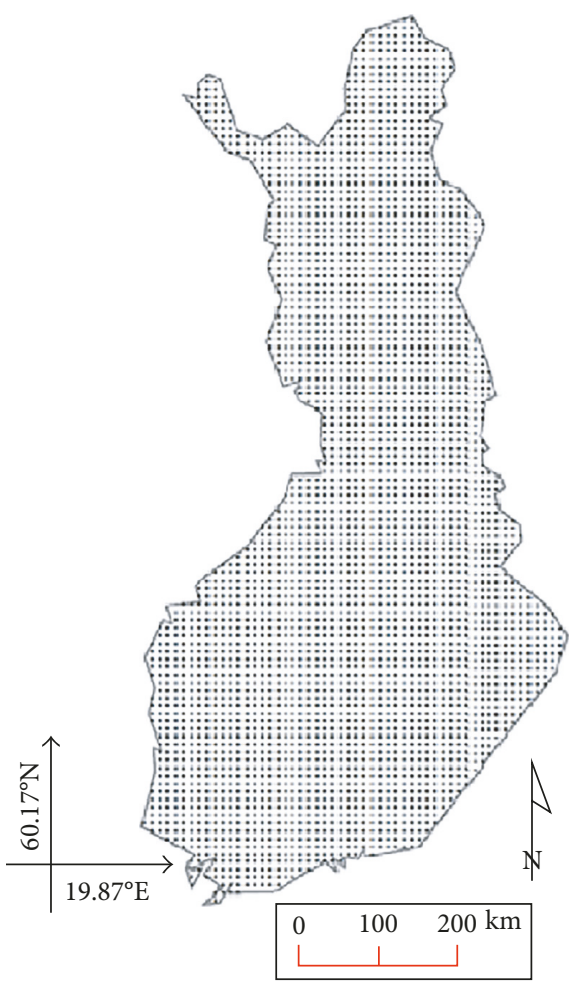

(c)

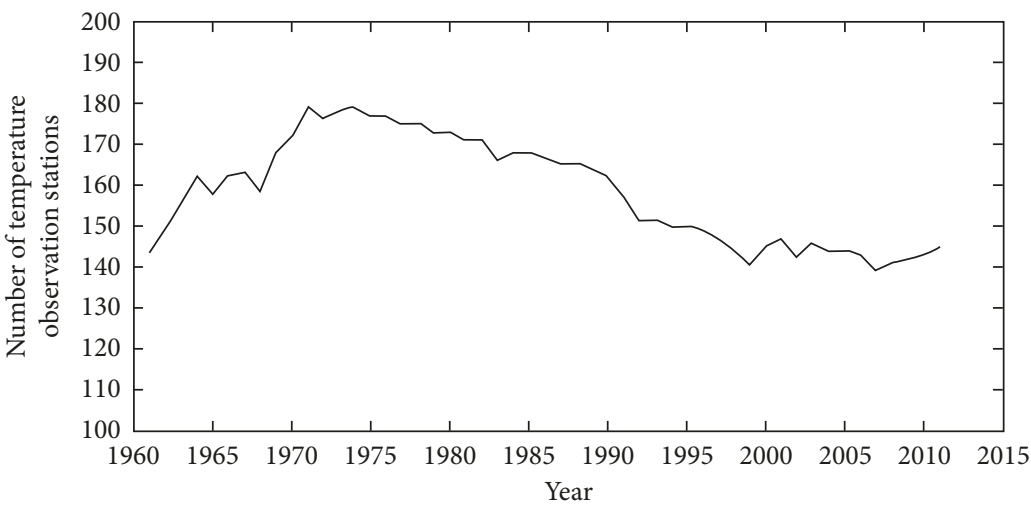

(e)

Figure 1: (a) Location of the study area, (b) different regions in Finland, (c) regular grid points $\left(10 \times 10 \mathrm{~km}^{2}\right)$ covering daily minimum and maximum temperature datasets across Finland obtained from PaiTuli, (d) daily temperature measurement stations in Finland used for calculation of the gridded time series, and (e) temporal variability in the number of daily temperature measurement stations in Finland over 1961-2011. 
TABLE 1: Definitions of selected daily extreme temperature indices and their period of Northern Hemisphere teleconnection patterns (NHTPs) for this study.

\begin{tabular}{lccccc}
\hline ID number & ID & Indicator name & Definition & Units & Period for NHTPs \\
\hline 1 & TXx & Maximum Tmax & Maximum value of daily maximum temperature (TX) & ${ }^{\circ} \mathrm{C}$ & Summer (Jun-Jul-Aug) \\
2 & TXn & Minimum Tmax & Minimum value of daily maximum temperature & ${ }^{\circ} \mathrm{C}$ & Winter (Dec-Jan-Feb) \\
3 & TNx & Maximum Tmin & Maximum value of daily minimum temperature (TN) & ${ }^{\circ} \mathrm{C}$ & Summer (Jun-Jul-Aug) \\
4 & TNn & Minimum Tmin & Minimum value of daily minimum temperature & ${ }^{\circ} \mathrm{C}$ & Winter (Dec-Jan-Feb) \\
5 & DTR & Diurnal temperature range & Annual mean difference between TX and TN & ${ }^{\circ} \mathrm{C}$ & Annual (Jan-Dec) \\
6 & ETR & Extreme temperature range & Annual difference between TXx and TNn & ${ }^{\circ} \mathrm{C}$ & Annual (Jan-Dec) \\
7 & FD & Frost days & Annual count of days when TN $<00^{\circ} \mathrm{C}$ & Days & Winter (Dec-Jan-Feb) \\
8 & ID & Icing days & Annual count of days when TX $<00^{\circ} \mathrm{C}$ & Days & Winter (Dec-Jan-Feb) \\
9 & SU25 & Summer days & Annual count of days when TX (daily maximum) & Days & Summer (Jun-Jul-Aug) \\
10 & TX10p & Cold days & Percentage of days when TX $<10$ th percentile & $\%$ & Winter (Dec-Jan-Feb) \\
11 & TX90p & Warm days & Percentage of days when TX $>90$ th percentile & $\%$ & Summer (Jun-Jul-Aug) \\
12 & TN10p & Cold nights & Percentage of days when TN $<10$ th percentile & $\%$ & Winter (Dec-Jan-Feb) \\
13 & TN90p & Warm nights & Percentage of days when TN $>90$ th percentile & $\%$ & Summer (Jun-Jul-Aug) \\
14 & WSDI & Warm spell duration & Annual count of days with at least six consecutive & Days & Summer (Jun-Jul-Aug) \\
& & & days when TX $>90$ th percentile & \\
15 & CSDI & Cold spell duration & Annual count of days with at least six consecutive & Days & Winter (Dec-Jan-Feb) \\
& & & days when TN $<10$ th percentile & &
\end{tabular}

TABle 2: Summary of the Northern Hemisphere teleconnection patterns (NHPs) affecting climate variability in Finland considered in this study.

\begin{tabular}{|c|c|c|c|}
\hline NHTP & Centre(s) of circulation & Natural signature over Finland in positive phase & Reference \\
\hline $\begin{array}{l}\text { North Atlantic } \\
\text { Oscillation } \\
\text { (NAO) }\end{array}$ & $\begin{array}{l}\text { Ponta Delagada (Azores) and } \\
\text { Stykkisholmur (Iceland) }\end{array}$ & $\begin{array}{l}\text { Strong westerly circulation bringing warmer and } \\
\text { wetter weather than normal }\end{array}$ & $\begin{array}{l}\text { Barnston and Livezey [38], } \\
\text { Irannezhad et al. [35, 39] }\end{array}$ \\
\hline $\begin{array}{l}\text { Arctic } \\
\text { Oscillation } \\
\text { (AO) }\end{array}$ & $\begin{array}{l}\text { A dipole between the polar cap } \\
\text { area and the adjacent zonal ring } \\
\text { centred along } 45^{\circ} \mathrm{N}\end{array}$ & $\begin{array}{l}\text { Low pressure in the Arctic and high pressure at } \\
\text { midlatitudes, leading to warmer and wetter weather } \\
\text { than normal }\end{array}$ & $\begin{array}{l}\text { Thompson and Wallace } \\
\text { [40], CPC [11], Irannezhad } \\
\text { et al. }[35,39]\end{array}$ \\
\hline $\begin{array}{l}\text { East Atlantic } \\
\text { (EA) }\end{array}$ & $\begin{array}{l}\text { North-south dipoles across the } \\
\text { North Atlantic }\end{array}$ & $\begin{array}{l}\text { Intensive westerly circulation, causing the weather to } \\
\text { be warmer and wetter than normal }\end{array}$ & $\begin{array}{l}\text { Barnston and Livezey [38], } \\
\text { CPC [41], Irannezhad et al. } \\
\qquad[35,39]\end{array}$ \\
\hline $\begin{array}{l}\text { West Pacific } \\
\text { (WP) }\end{array}$ & $\begin{array}{c}\text { Kamchatka (Russia) and a centre } \\
\text { between the western, North } \\
\text { Pacific, and South Asia and East } \\
\text { Asia }\end{array}$ & $\begin{array}{l}\text { North-south dipole anomalies causing the weather to } \\
\text { be wetter than normal in February and colder than } \\
\text { normal in spring and summer }\end{array}$ & Irannezhad et al. $[35,39]$ \\
\hline $\begin{array}{l}\text { East Atlantic/ } \\
\text { West Russia } \\
\text { (EA/WR) }\end{array}$ & $\begin{array}{l}\text { Western Europe, northwest } \\
\text { Europe, and Portugal in spring } \\
\text { and autumn; Caspian Sea in } \\
\text { winter and Russia }\end{array}$ & $\begin{array}{c}\text { Northerly and northwesterly circulation across the } \\
\text { Baltic Sea, resulting in milder and drier weather than } \\
\text { normal }\end{array}$ & $\begin{array}{l}\text { Barnston and Livezey [38], } \\
\text { Lim and Kim [42], } \\
\text { Irannezhad et al. [35, 39] }\end{array}$ \\
\hline $\begin{array}{l}\text { Scandinavia } \\
\text { (SCA) }\end{array}$ & $\begin{array}{l}\text { West of Europe, Mongolia, and } \\
\text { Scandinavia }\end{array}$ & $\begin{array}{l}\text { High pressure over Scandinavia, bringing milder and } \\
\text { drier weather than normal }\end{array}$ & $\begin{array}{l}\text { Barnston and Livezey [38], } \\
\text { Bueh and Nakamura }[43] \text {, } \\
\text { Irannezhad et al. }[35,39]\end{array}$ \\
\hline $\begin{array}{l}\text { Polar/Eurasia } \\
\text { (POL) }\end{array}$ & $\begin{array}{l}\text { North Pole, Europe, and } \\
\text { northeastern China, }\end{array}$ & $\begin{array}{c}\text { Strong polar vortex resulting in milder and drier } \\
\text { weather than normal }\end{array}$ & $\begin{array}{c}\text { CPC [41], Irannezhad et al. } \\
{[35,39]}\end{array}$ \\
\hline
\end{tabular}

2.2. Statistical Analyses. The Mann-Kendall (MK) nonparametric test $[44,45]$ was applied for detecting statistically significant $(p<0.05)$ trends in extreme temperatures. To identify relationships between extreme temperature indices in Finland and NHTPs during 1961-2011, Spearman's rank correlation $(\rho)$ was used. However, for autocorrelated time series, the trend free prewhitening (TFPW) method [46] to detect significant $(p<0.05)$ trends and the residual bootstrap (RB) approach [47] with 5000 independent replications to estimate the standard deviation of the $\rho$ values were applied. Using the Sen method [48], the present study calculated the slope of detected significant trends as an estimate of the trend.
To assess the uncertainties associated with the estimated trends, their 95\% confidence intervals were calculated [49].

\section{Results}

3.1. Country Scale Assessment of Extreme Temperatures. Number of warm days (TX90p) and nights (TN90p) on the country scale significantly increased by $0.8 \pm 0.4$ and $1.4 \pm$ 0.7 (\% per decade, $p<0.05$ ) during 1961-2011, but cold days (TX10p) and nights (TN10p) decreased by $1.2 \pm 0.7$ and $1.3 \pm 0.7$ (\% per decade, $p<0.05$ ), respectively (Figures $2(\mathrm{a})-2(\mathrm{~d}))$. The maximum number of events during a year 


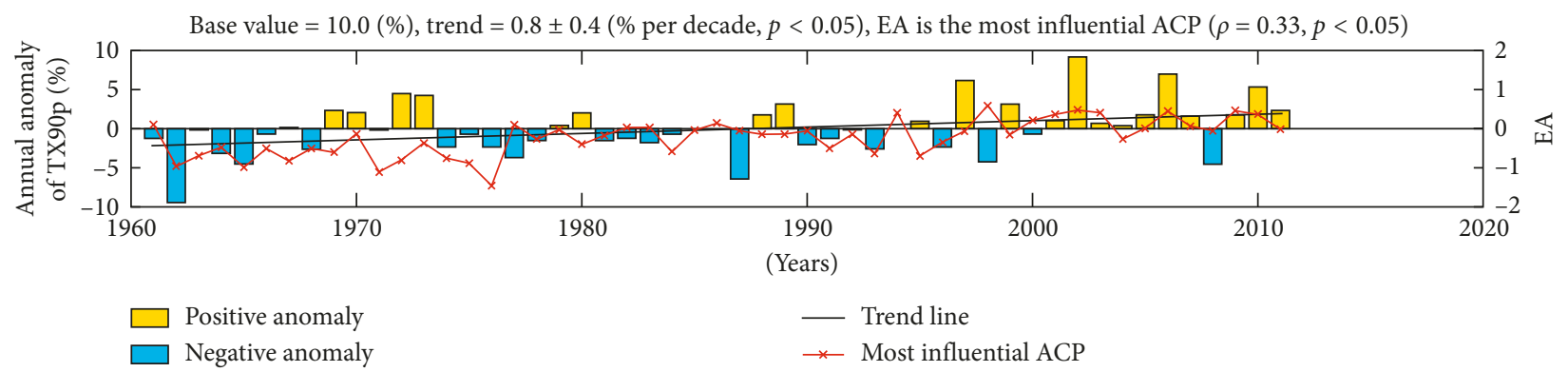

(a)

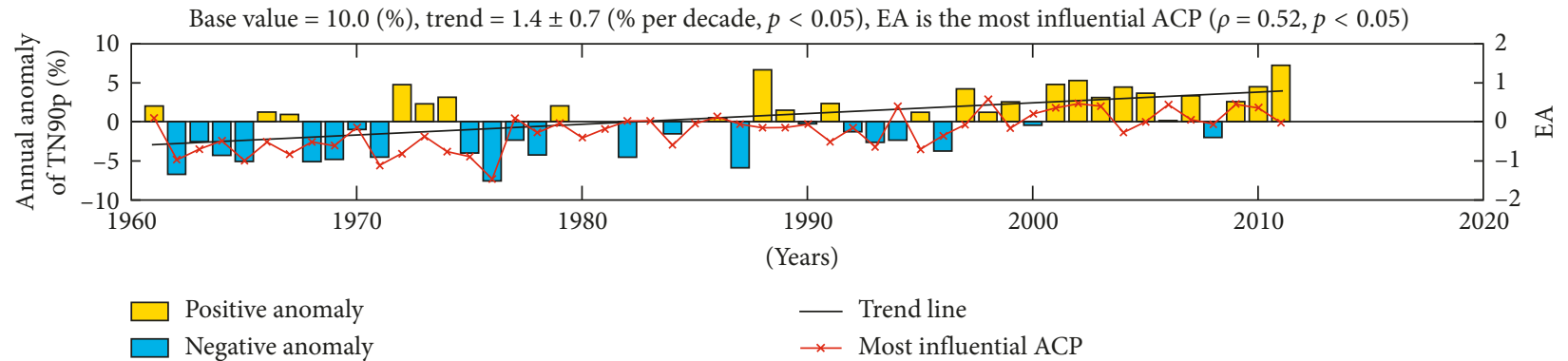

(b)

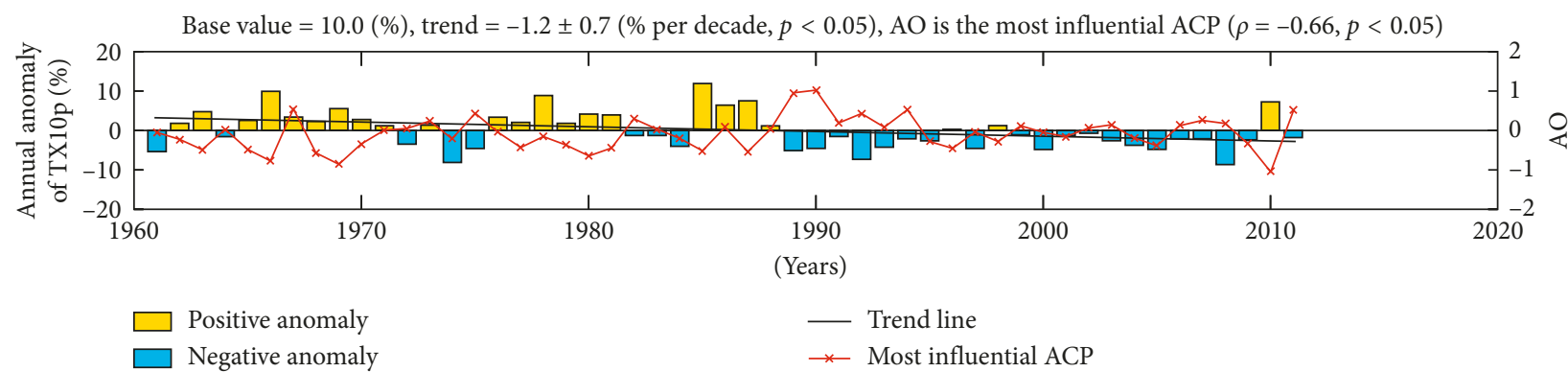

(c)

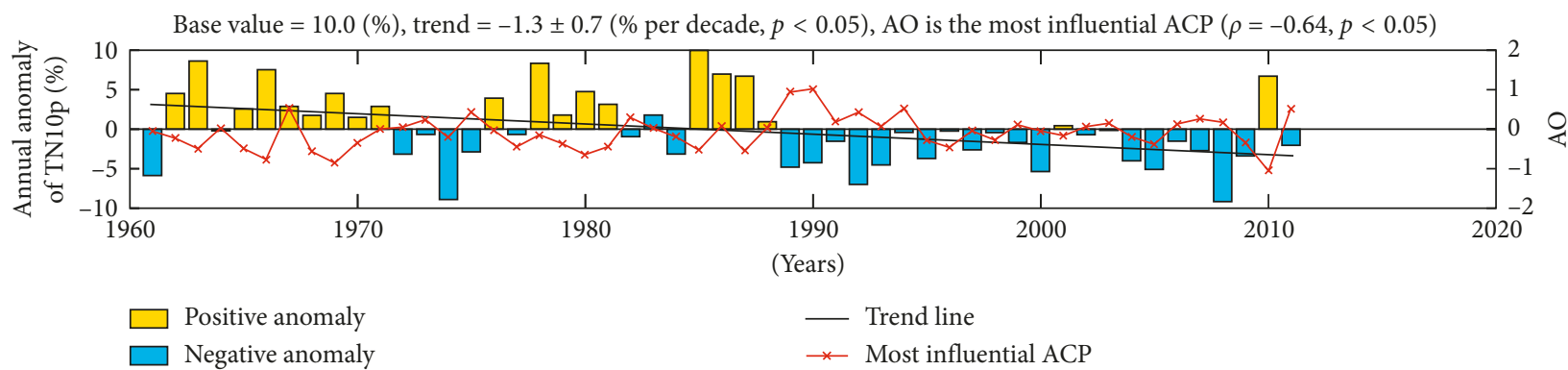

(d)

FIGURE 2: Time series with trend line and most influential NHTP for (a) TX90p, (b) TN90p, (c) TX10p, and (d) TN10p, on the country scale in Finland during 1961-2011.

for warm days was about 70 days (19.2\%) in 2007 (Figure 2(a)); for warm nights was almost 63 days (17.3\%) in 2011 (Figure 2(b)); and for cold days and nights was correspondingly equal to $80(21.9 \%)$ and $73(20 \%)$ days, both in 1985 (Figures 2(c) and 2(d)). The EA pattern was the most influential NHTP for variations in both warm days $(\rho=0.33)$ and nights $(\rho=0.52)$ and the AO for variability in both cold days $(\rho=-0.66)$ and nights $(\rho=-0.64)$ (Table 3$)$.

On country scale, significant decreasing trends were detected in frost (FD) and icing (ID) days during
1961-2011, at the rates of $-4.7 \pm 2.7$ and $-3.6 \pm 3.2$ (days/decade, $p<0.05$ ), respectively (Figures 3(a) and 3(b)). The base value was 200.1 days for the annual FD and about 117 days for the annual ID (Table 3). The annual FD varied from 172 days in 2000 to 230 days in 1968 (Figure 3(a)), and the annual ID ranged between 77 days in 1975 and 148 days in 1980 (Figure 3(b)). Such variations in the annual FD and ID were most significantly correlated with the NAO $(\rho=-0.28)$ and the AO $(\rho=-0.49)$ patterns, in turn (Table 3$)$. 
TABLE 3: Base value (average during 1961-2011), statistically significant $(p<0.05)$ trends, and Spearman rank correlation $(\rho)$ with NHTPs for daily extreme temperature indices given in Table 1.

\begin{tabular}{|c|c|c|c|c|c|c|c|c|c|c|c|}
\hline ID number & ID & Unit & Base value & Trend (/decade, $p<0.05)$ & $\mathrm{NAO}$ & EA & WP & EA/WR & SCA & POL & $\mathrm{AO}$ \\
\hline 1 & TXx & ${ }^{\circ} \mathrm{C}$ & 26.7 & - & -0.05 & 0.21 & -0.06 & -0.02 & 0.39 & 0.28 & 0.01 \\
\hline 2 & TXn & ${ }^{\circ} \mathrm{C}$ & -20.0 & - & 0.35 & -0.21 & -0.15 & 0.01 & -0.22 & -0.16 & 0.32 \\
\hline 3 & $\mathrm{TNx}$ & ${ }^{\circ} \mathrm{C}$ & 14.9 & $0.3 \pm 0.2$ & 0.01 & 0.55 & -0.22 & -0.37 & 0.11 & -0.02 & 0.18 \\
\hline 4 & $\mathrm{TNn}$ & ${ }^{\circ} \mathrm{C}$ & -29.3 & - & 0.47 & -0.12 & -0.04 & 0.10 & -0.19 & -0.22 & 0.41 \\
\hline 5 & DTR & ${ }^{\circ} \mathrm{C}$ & 8.2 & $-0.09 \pm 0.08$ & -0.35 & -0.23 & 0.07 & 0.33 & 0.17 & 0.19 & -0.28 \\
\hline 6 & ETR & ${ }^{\circ} \mathrm{C}$ & 56.0 & - & -0.10 & 0.07 & 0.21 & 0.14 & 0.06 & 0.06 & -0.13 \\
\hline 7 & FD & days & 200.1 & $-4.7 \pm 2.7$ & -0.28 & -0.04 & -0.21 & 0.04 & 0.08 & 0.22 & -0.11 \\
\hline 8 & ID & days & 117.0 & $-3.6 \pm 3.2$ & -0.39 & -0.05 & -0.12 & -0.18 & 0.10 & -0.07 & -0.49 \\
\hline 9 & SU25 & days & 5.3 & - & 0.01 & 0.27 & -0.13 & -0.07 & 0.39 & 0.21 & 0.07 \\
\hline 10 & TX10p & $\%$ & 10.0 & $-1.2 \pm 0.7$ & -0.64 & -0.01 & 0.09 & -0.23 & 0.28 & 0.11 & -0.66 \\
\hline 11 & TX90p & $\%$ & 10.0 & $0.8 \pm 0.4$ & 0.07 & 0.33 & -0.28 & -0.17 & 0.27 & 0.20 & 0.21 \\
\hline 12 & TN10p & $\%$ & 10.0 & $-1.3 \pm 0.7$ & -0.62 & -0.03 & -0.14 & -0.16 & 0.23 & 0.17 & -0.64 \\
\hline 13 & TN90p & $\%$ & 10.0 & $1.4 \pm 0.7$ & -0.05 & 0.52 & -0.42 & -0.48 & 0.07 & -0.10 & 0.11 \\
\hline 14 & WSDI & days & 42.0 & - & 0.17 & -0.34 & 0.24 & 0.16 & 0.14 & -0.11 & -0.13 \\
\hline 15 & CSDI & days & 286.5 & - & 0.42 & 0.07 & -0.13 & -0.08 & -0.23 & -0.02 & 0.35 \\
\hline
\end{tabular}

If significant $(p<0.05), \rho$ is given in bold.

Diurnal temperature range (DTR) has slightly decreased by $0.09 \pm 0.08\left({ }^{\circ} \mathrm{C} /\right.$ decade, $\left.p<0.05\right)$, while maximum Tmin (TNx) has increased by $0.30 \pm 0.20\left({ }^{\circ} \mathrm{C} /\right.$ decade, $\left.p<0.05\right)$ (Figures 3(c) and 3(d)). On average, the annual DTR was about $8.2^{\circ} \mathrm{C}$ and ranged from $7.3^{\circ} \mathrm{C}$ in 2008 and $9.4^{\circ} \mathrm{C}$ in 1963 (Figure $3(\mathrm{c}))$. The NAO was the strongest $(p<0.05)$ NHTP affecting the variability of DTR, with $\rho=-0.35$ (Table 3 ). With the base value of $14.9^{\circ} \mathrm{C}$, the annual TNx varied between $11.7^{\circ} \mathrm{C}$ in 1962 and $18.5^{\circ} \mathrm{C}$ in 2003 and showed the strongest relationships with the EA pattern $(\rho=0.55$, $p<0.05$ ) (Figure 3(d)). Other indices related to the extreme temperature intensity (TXx, TXn, TNn, and ETR in Table 1) and frequency (SU25 in Table 1) showed no clear trends (Table 3). For such extreme temperatures, wintertimedependent indices (TXn and TNn) were most significantly associated with the NAO index and summertime indices (TXx and SU25) with the SCA pattern (Table 3). However, no clear connections between ETR and NHTPs were found (Table 3).

On average, annual warm (WSDI) and cold (CSDI) spells were 42.0 and 286.5 days, respectively (Table 3 ). The longest WSDI (CSDI) was 77 (358) days in 1963 (1974), and the shortest was 10 (19) days in 1986 (2008). The EA pattern was the most influential NHTP for the WSDI variability $(\rho=-0.34)$, while the CSDI showed strongest relationships with the NAO $(\rho=0.42)$ (Table 3$)$. Besides, trend analysis indicates no statistically significant changes in warm and cold spells (Table 3 ).

\subsection{Spatial Distribution of Warm and Cold Temperature} Indices. In general, TXx was warmer (ranging 28.0$30.0^{\circ} \mathrm{C}$ ) over the southern, eastern, and western Finland (Figure $4(\mathrm{a})$ ), while $\mathrm{TNx}$ was warmer (ranging $17.3-18.5^{\circ} \mathrm{C}$ ) mostly in the east of country (Figure 4(c)). The warmest range for both TXn (from -14.0 to $-10.0^{\circ} \mathrm{C}$ ) and $\mathrm{TNn}$ (from -23.0 to $-20.0^{\circ} \mathrm{C}$ ) was seen over the southwest coastal areas of Finland (Figures 4(b) and 4(d)). The highest range for DTR was $8.3-9.5^{\circ} \mathrm{C}$ largely observed in the north, centre, west, and south (Figure 4(e)), and for ETR was between 60.8 and $66.0^{\circ} \mathrm{C}$ seen over the northern, central, and eastern parts (Figure 4(f)). Both FD and ID were more frequent at the higher latitudes, with the highest range of 225-250 (Figure 5(a)) and 165-205 (Figure 5(b)) days, respectively. In contrast, the highest frequency range (15-20 events) of summer days (SU25 in Table 1) was found in the south (Figure 5(c)). All TX10p, TX90p, TN10p, and TN90p obviously ranged between 9.5 and $10.0 \%$ of days during a year ( $255-37$ days) scattered over Finland (not shown). The longest warm spell ranging from 52 to 57 days was observed in the southern areas of Finland (Figure 5(d)), and the longest cold spell ranging between 285 and 305 days was located in the northern and central parts (Figure 5(e)).

Significant $(p<0.05)$ spatial trends determined in TXx, TXn, TNx, and TNn during 1961-2011 were all positive (Figures 6(a)-6(d)). Such warming trends in TXx were observed over small areas in southern and western Finland (Figure 6(a)); in TXn across the large parts of the northern and western Finland (Figure 6(b)); in TNx mostly throughout the entire country except central parts (Figure 6(c)); and in TNn mainly over the southern, western, and northern Finland (Figure 6(d)). For both diurnal (Figure 6(e)) and extreme (Figure 7(a)) temperature ranges (DTR and ETR), significant decreases are primarily observed over the northern parts and southwestern coastal areas of Finland. During 1961-2011, the range of such trends was from -0.50 to $-0.25\left({ }^{\circ} \mathrm{C} /\right.$ decade $)$ for DTR (Figure 6(e)) and from -3 to $-1\left({ }^{\circ} \mathrm{C} /\right.$ decade) for ETR (Figure 7(a)). The highest rate of decreasing trends in FD (5.3-10.6 days/decade) was seen over some areas in the southern, eastern, western, and central Finland (Figure 7(b)). For ID, significant decreasing trends, ranging from -1.2 to -7.2 (days/decade), were largely observed over the west and north of the country (Figure 7(c)). All significant trends in SU25 found mainly in the southern Finland were positive, ranging between 1.6 and 3.2 (days/decade) (Figure 7(d)). Both TX10p (Figure 7(e)) and TN10p (Figure 8(b)) showed decreases over most parts 


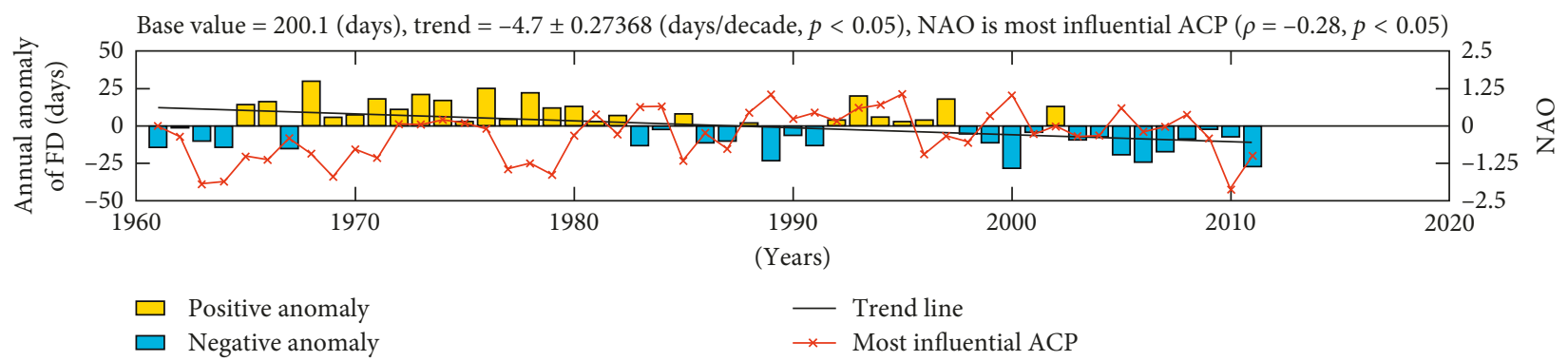

(a)

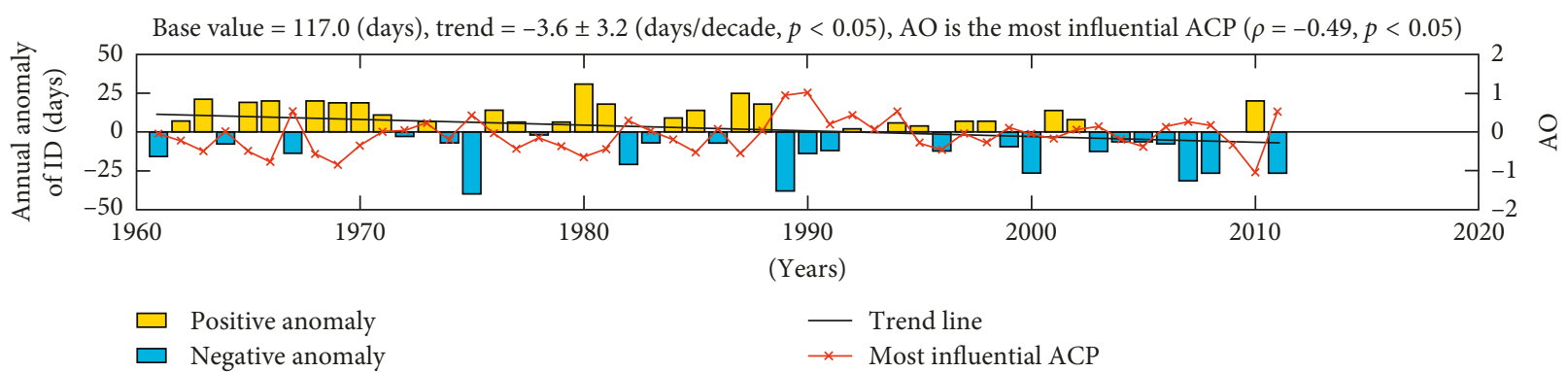

(b)

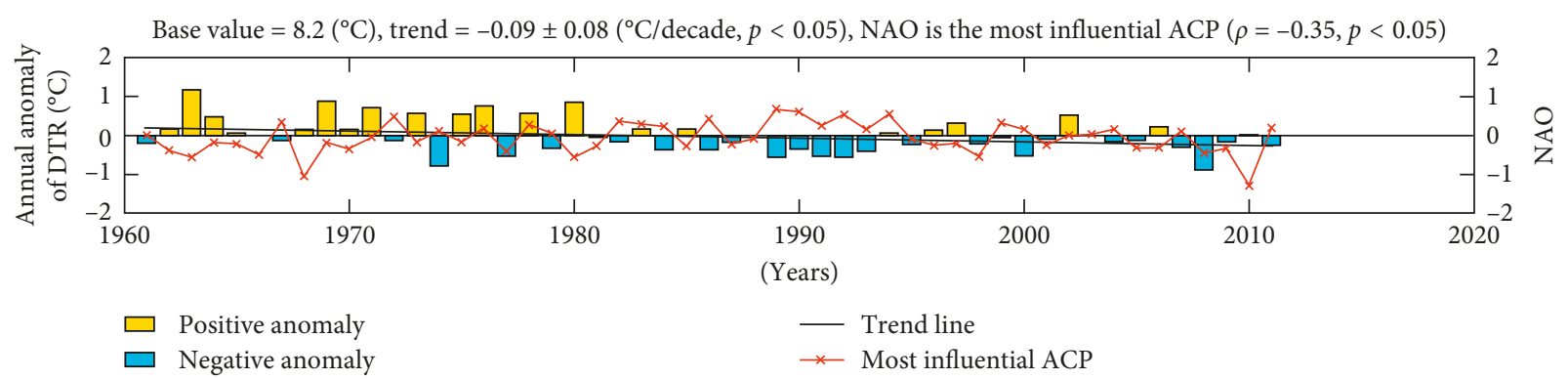

(c)

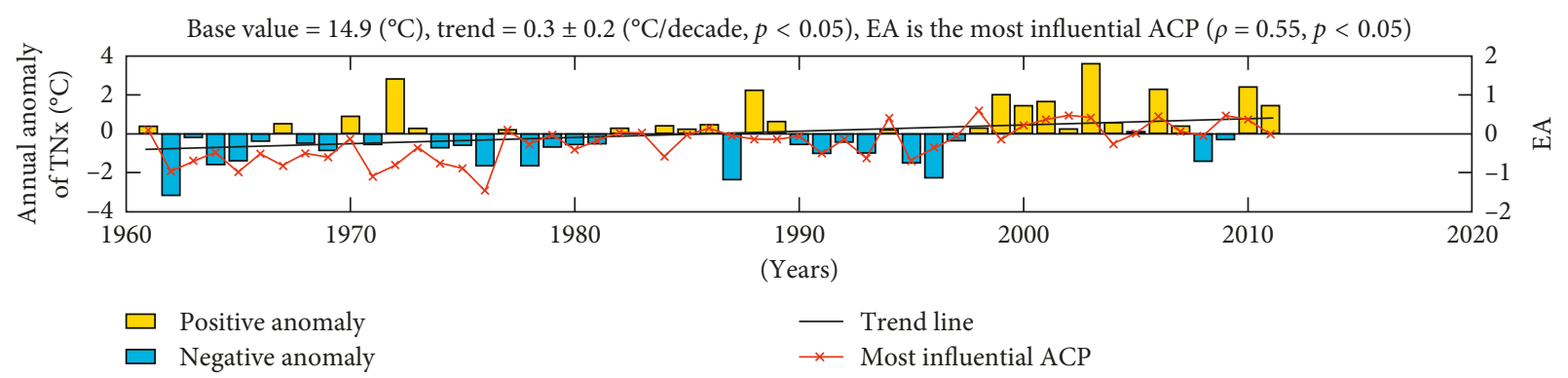

(d)

Figure 3: Time series with trend line and most influential NHTP for (a) FD, (b) ID, (c) DTR, and (d) TNx, on the country scale in Finland during 1961-2011.

of Finland, but both TX90p (Figure 8(a)) and TN90p (Figure $8(\mathrm{c})$ ) revealed increasing trends. WSDI significantly increased at a few grids in the western Finland (Figure $8(\mathrm{~d})$ ), while increases in CSDI were mainly found in the northern Finland (Figure 8(e)).

TXx showed significant positive correlations with the SCA pattern in the north, centre, east, and upper west of Finland, with the EA pattern over the lower parts of western Finland and with the POL pattern in the south of Finland (Figure 9(a)). The EA and SCA patterns were also the most influential NHTPs for TNx and SU25 in most parts of
Finland, respectively (Figures 9(b) and 9(c)). Besides, TX90p showed strong positive correlations with the EA pattern in the northern and centre of Finland, while with the SCA pattern in other parts of the country (Figure 9(d)). Both TN90p and WSDI in the northern Finland were significantly associated with the EA pattern (Figures 9(e) and 9(f)). However, the EA/WR pattern was the most significant NHTPs affecting TN90p in most parts of the central, eastern, and western Finland (Figure 9(e)). On the contrary, the POL pattern was the most influential NHTP for variations in SU25 and WSDI in the south of Finland (Figures 9(c) and 9(f)). 


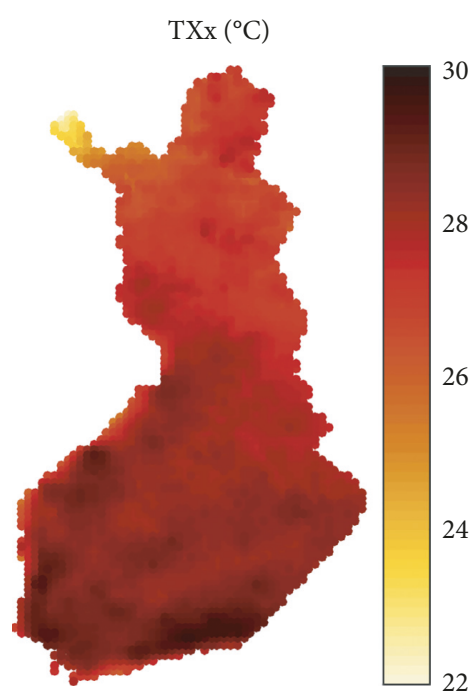

(a)

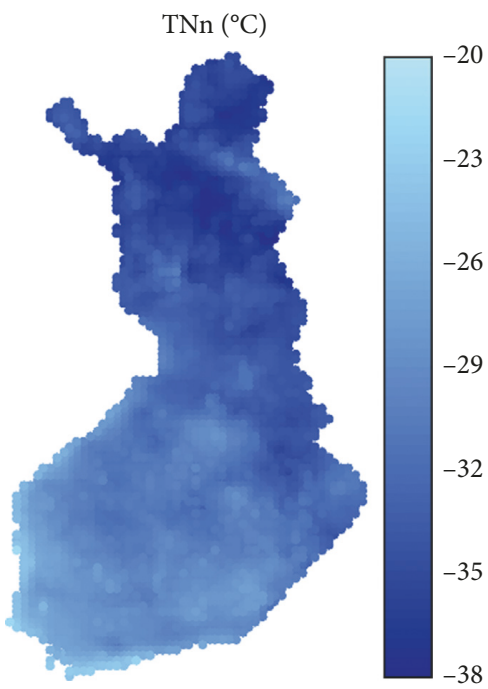

(d)

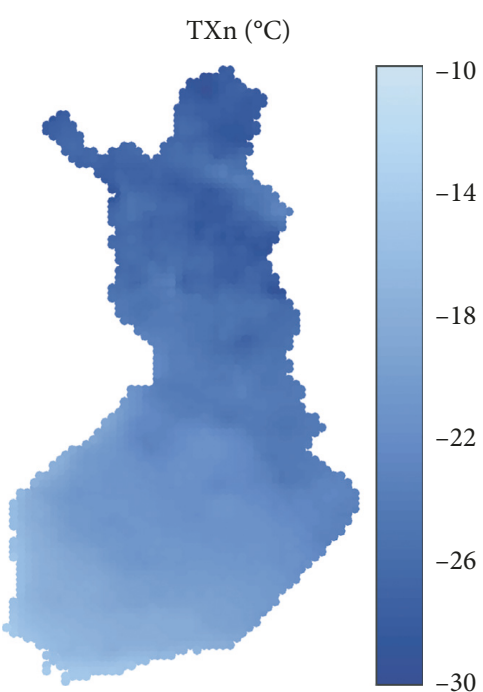

(b)

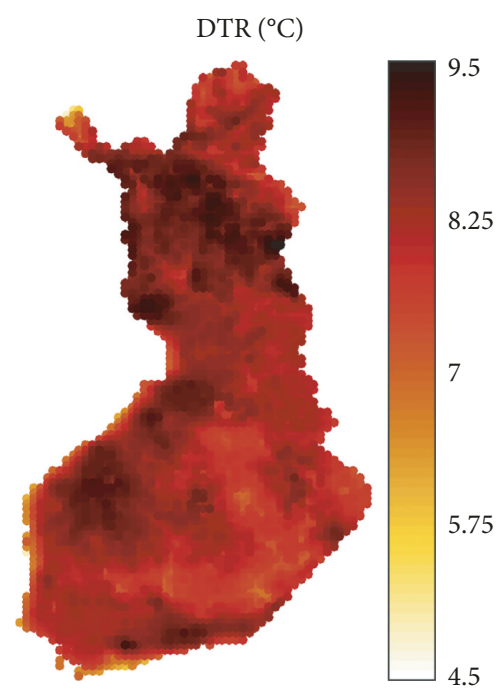

(e)

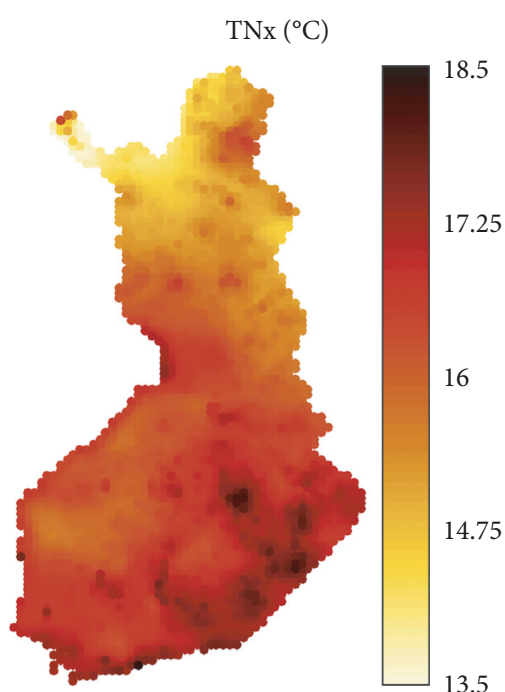

(c)

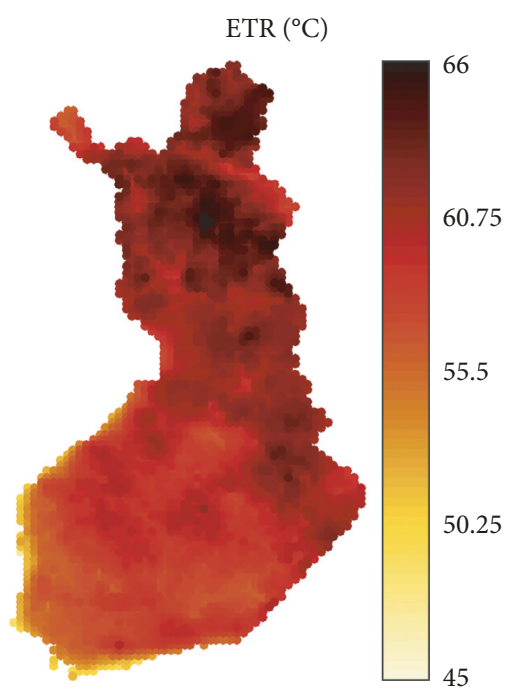

(f)

FIGURE 4: Spatial distribution maps of base values for (a) TXx, (b) TXn, (c) TNx, (d) TNn, (e) DTR, and (f) ETR in Finland during $1961-2011$.

In general, variations in cold temperature extreme indices (TXn, TNn, FD, ID, TX10p, TN10p, and CSDI) in Finland were significantly correlated with the NAO and AO (Figure 10). The AO showed negative associations with ID and TX10p over most parts of Finland (Figures 10(d) and $10(\mathrm{e}))$. It (AO) also influenced TN10p in the country except the eastern parts of the northern and central Finland, where the NAO was the most influential NHTP (Figure 10(f)). Likewise, the NAO was the only strong NHTP affecting FD in the southern, western, and eastern areas (Figure 10(c)) as well as CSDI in the northern, central, and some parts of eastern and western Finland (Figure 10(g)). This NHTP (NAO), besides, was in strong associations with TXn in most parts of eastern, western, northern, and southern Finland, while TXn in central areas were significantly linked to the AO index (Figure 10(a)). Similarly, TNn strongly correlated with the AO index in small areas mainly scattered over the eastern, western, southern, central, and western parts of northern Finland, while the NAO was the most influential NHTP for TNn throughout other areas of the country (Figure 10(b)).

DTR was negatively correlated with the NAO mostly in the northern and central Finland, while positively with the EA/WR pattern in the western, southern, and eastern areas (Figure 11(a)). On the contrary, ETR showed positive correlations with the WP pattern in the northern, western, and southern Finland; with the EA pattern in central and western parts; and the EA/WR pattern in small areas throughout the north of the country (Figure 11(b)).

\section{Discussion}

4.1. Changes in Extreme Temperatures. Study of changes in intensity, frequency, and duration of extreme temperatures in response to climate warming has received a substantial attention around the world in recent years (e.g. $[2,6,7])$. Using 


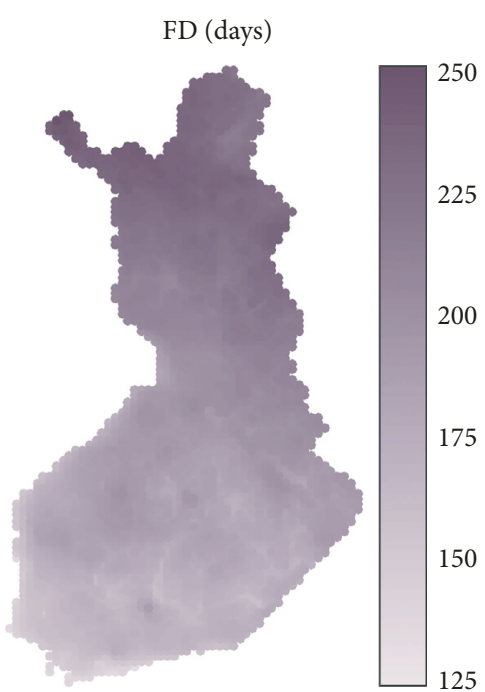

(a)

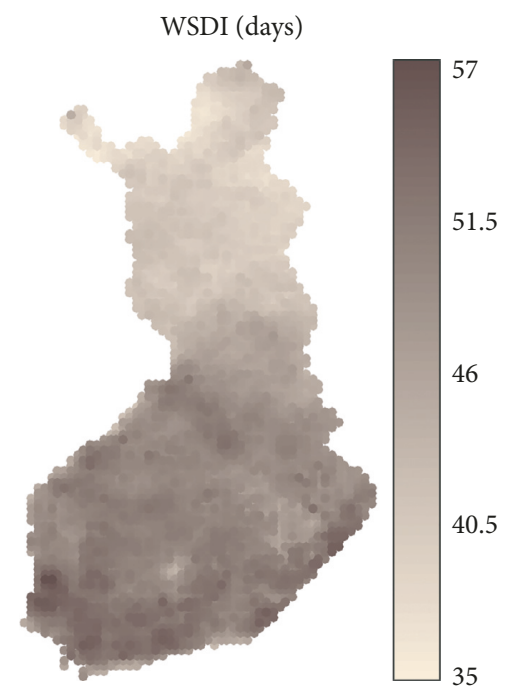

(d)

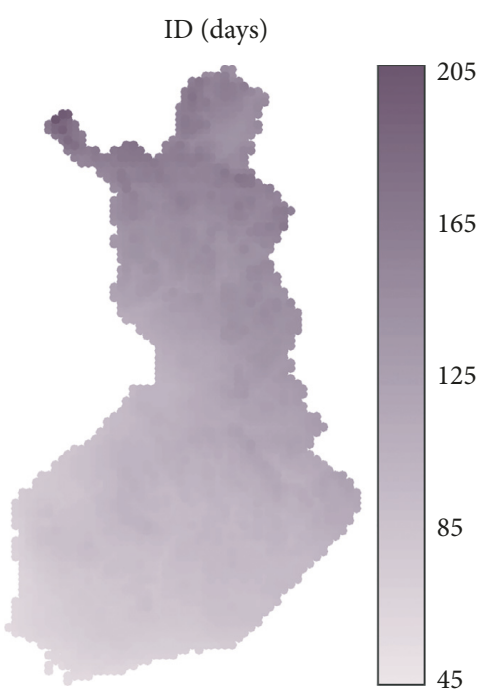

(b)

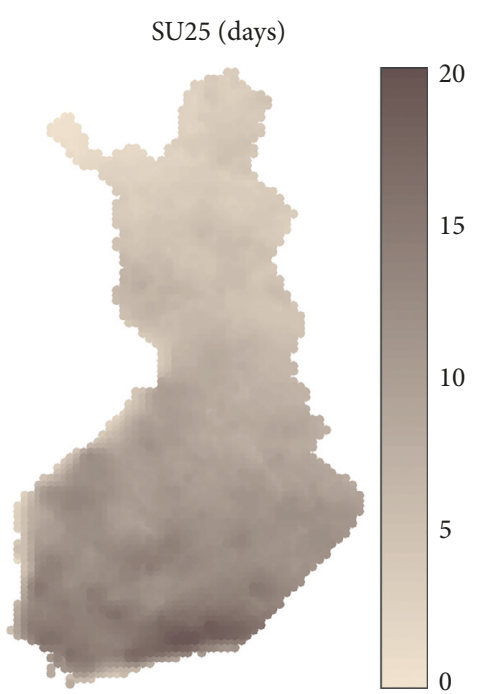

(c)

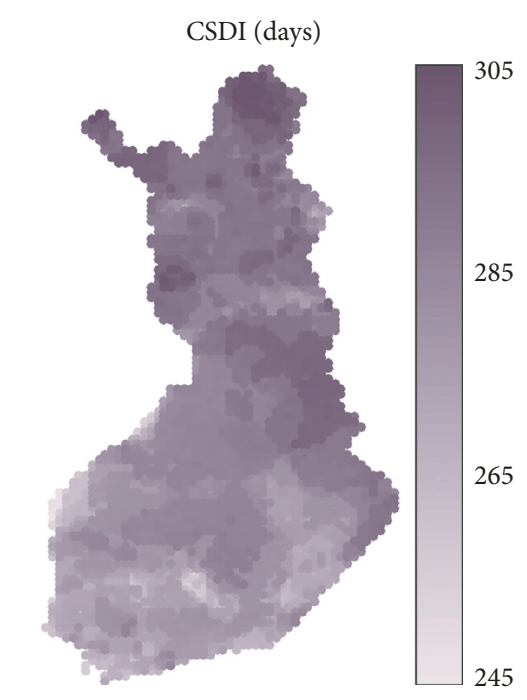

(e)

FIgUre 5: Spatial distribution maps of base values for (a) FD, (b) ID, (c) SU25, (d) WSDI, and (e) CSDI in Finland during 1961-2011.

daily extreme temperature indices recommended by ETCCDI, this paper evaluated interannual variability and trends in warm and cold extreme events in Finland during 1961-2011. Intensification of warm extreme temperatures in Finland was generally manifested by significant increasing trends detected in TNx over most parts of the country. For cold extreme temperatures, warming trends revealed by the TXn and TNn indices were largely seen over the southwest and north of Finland. Difference in the rate of such increasing trends in warm and cold extreme temperatures caused DTR and ETR indices to decline, particularly over the southwestern and northern Finland. Such decreases in DTR and ETR are generally referred to increases in the cold temperature extreme indices. In fact, extreme temperature warming in Finland results primarily from rises in the cold temperature extreme indices than in the warm ones. Similarly, Alexander et al. [6] reported warming trends in minimum temperature extremes were greater than in maximum temperature extremes over many parts of the world. Chen et al. [2] also concluded that the intensity of extreme temperatures has increased over the northern Europe associated with mean temperature rise over the 20th century. Likewise, previous studies reported statistically significant warming trends over Finland during the last century (e.g., $[25,50])$.

This study determined that warm temperature extremes have become more frequent in Finland over 1961-2011, reflected by the statistically significant increasing trends in warm days (TX90p) and nights (TN90p). Also, lower frequency of cold temperature extremes were manifested by statistically significant decreasing trends in frost (FD) and icing (ID) days as well as cold days (TX10p) and nights (TN10p). Similar to these findings, Alexander et al. [6] concluded more (less) frequent warm (cold) days and nights at the global scale. For 


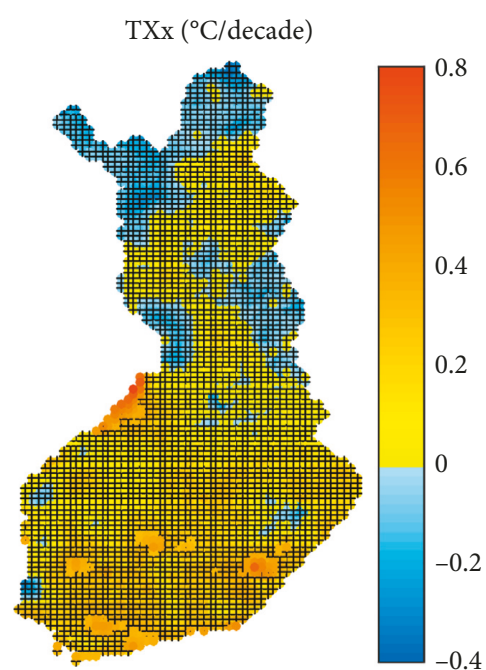

(a)

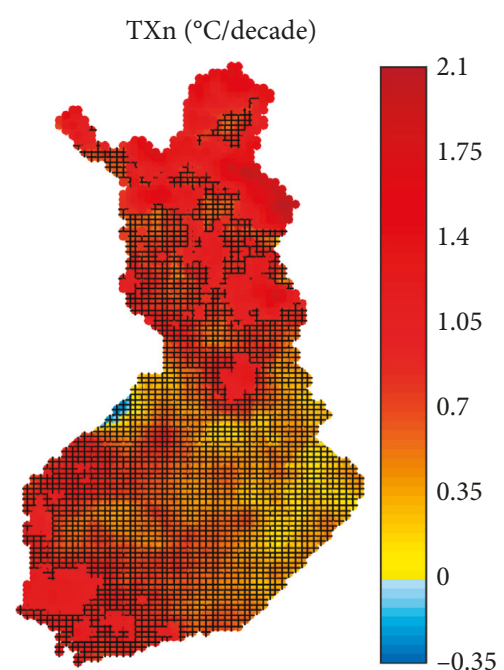

(b)

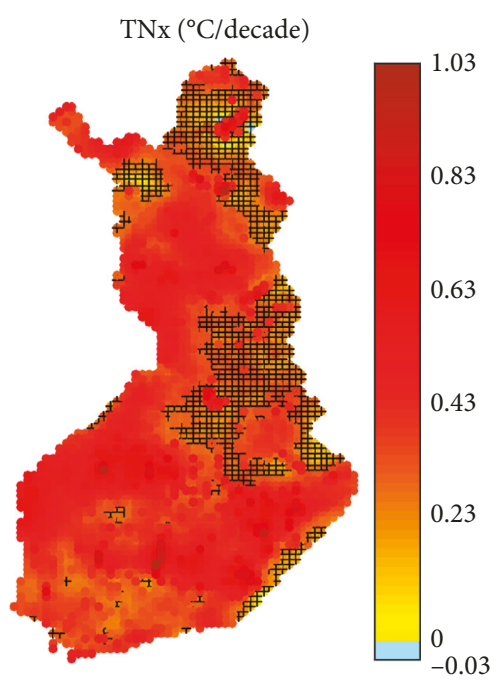

(c)

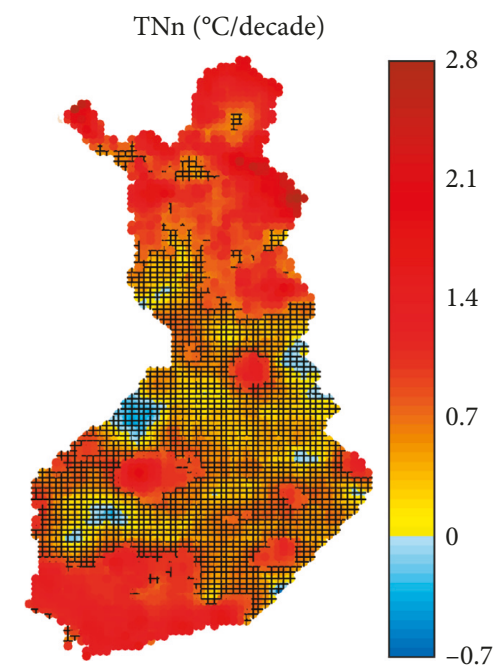

(d)

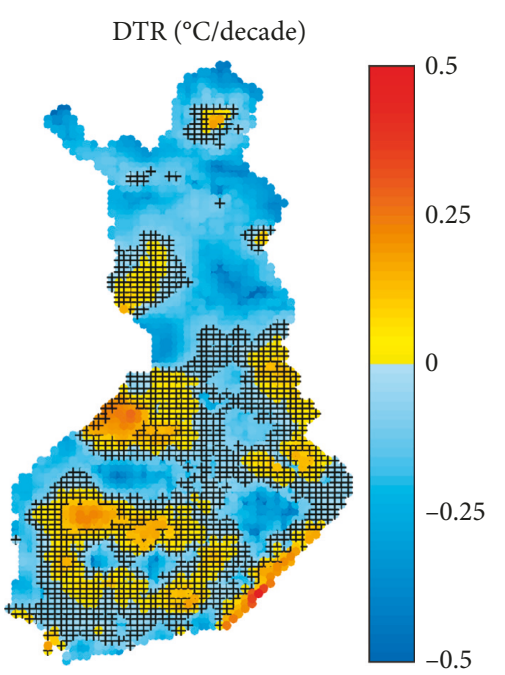

(e)

Figure 6: Spatial distribution maps of trends (/decade) in (a) TXx, (b) TXn, (c) TNx, (d) TNn, and (e) DTR in Finland during $1961-2011$. The stippling indicates areas where the trends are statistically insignificant $(p>0.05)$.

the north of Chen et al. [2] also determined increases (decreases) in the frequency of high- (low-) temperature extreme events during 1901-2000.

On national scale, there were no clear changes in warm and cold spells during 1961-2011. However, spatial trend analysis indicates significant increases in cold spells in the upper parts of the northern Finland. On the contrary, Alexander et al. [6] reported that cold (warm) spells over Finland have slightly shortened (lengthened) over the period 1951-2003. For the northern Finland, Chen et al. [2] concluded significant lengthening in the warm spells only during the winter season (December-February) over the years 1901-2000, while shortening in the cold spells in the summer (June-August) and autumn (September-November) seasons. Such differentiated changes identified by these studies confirm that extreme temperature events are spatially and temporally inhomogeneous.
4.2. Influence of Northern Hemisphere Teleconnection Patterns. The present study indicates that warm temperature extreme events (TXx, TNx, SU25, TX90p, TN90p, and WSDI) were mostly controlled by the EA and SCA patterns. Similarly, Irannezhad et al. [25] concluded that the EA and SCA patterns are the first and second most significant NHTPs positively influencing variability in temperature over summer season in Finland. The EA pattern is originally defined by Wallace and Gutzler [51] as a teleconnection with four different action centres: two low pressures in the west of the British Islands and over central Serbia and two high pressures in the southwest of the Canary Islands and between the Caspian and Black Seas, respectively [52]. It principally describes the airflow coming from the Biscayan towards the centre of Europe. Hence, the EA positive phase results in a negative pressure anomaly over the western Ireland and a positive pressure anomaly from the western to 


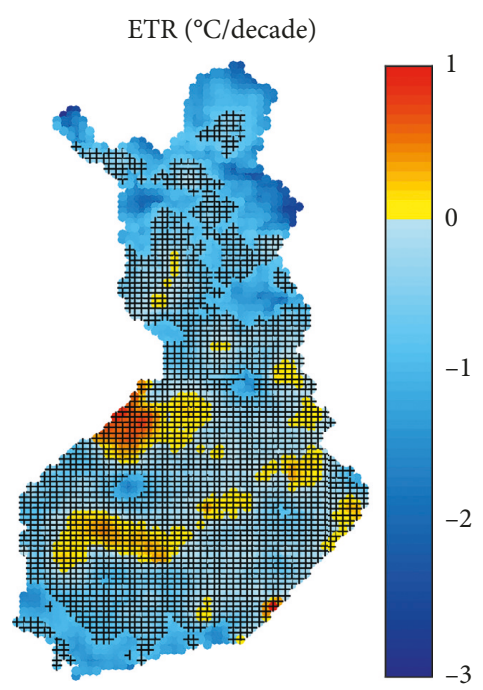

(a)

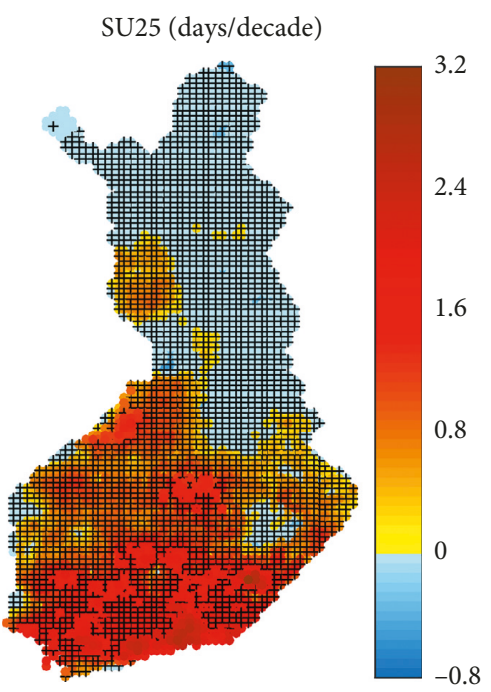

(d)

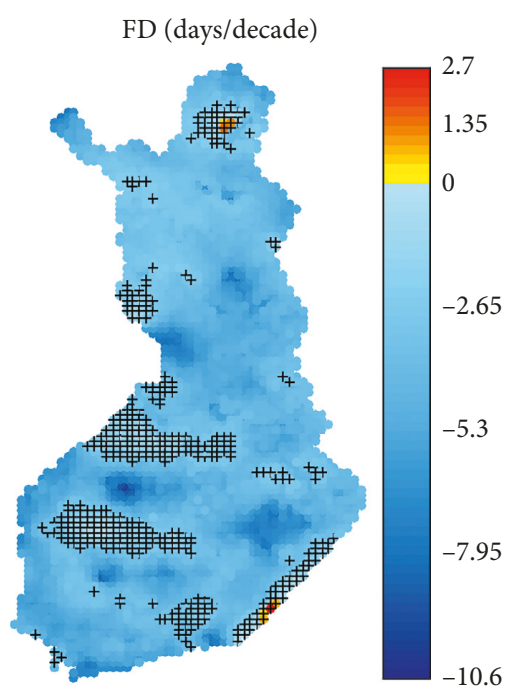

(b)

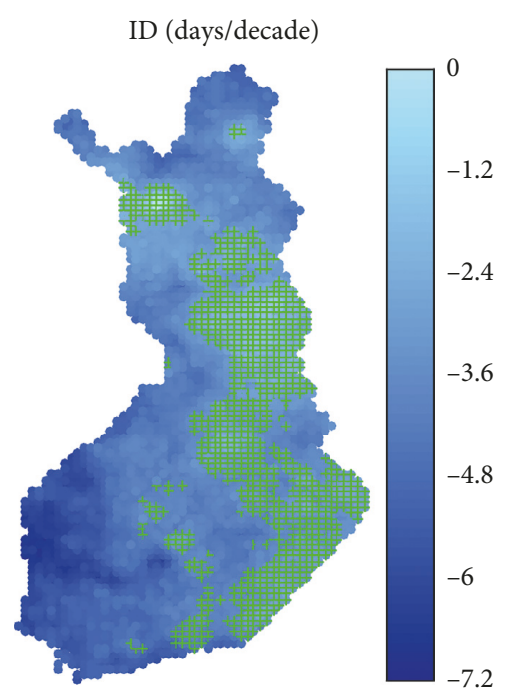

(c)

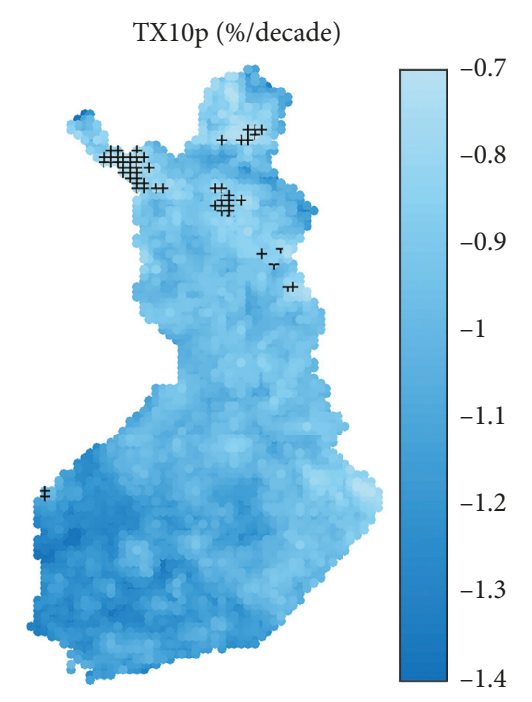

(e)

Figure 7: Spatial distribution maps of trends (/decade) in (a) ETR, (b) FD, (c) ID, (d) SU25, and (e) TX10p in Finland during 1961-2011. The stippling indicates areas where the trends are statistically insignificant $(p>0.05)$.

the eastern Atlantic, which brings warmer airflow than normal to Finland. Irannezhad et al. [25] also showed that the predominant surface wind over Finland during summer under the positive EA is from the south direction, which brings warm air from the southern Europe to Finland and thereby controlling warm extreme temperature events over the country. For the SCA pattern, the main action centre is located over Scandinavia and large parts of the Arctic Ocean in the north of Siberia, while two other centres are across the west of Europe and the west of China. The positive (negative) SCA refers to high- (low-) pressure system throughout Greenland, Norwegian Sea, and Scandinavia [43] resulting in warmer (colder) climate in, particularly during warm months of the year, Finland [25].

Cold temperature extreme indices (including TXn, TNn, FD, ID, TX10p, TN10p, and CSDI) showed most significant correlations with the AO and the NAO patterns. Similar to this study, Irannezhad et al. [25] identified the AO and the
NAO pattern as the most influential NHTPs for variability in the mean temperature over Finland, particularly during winter. The AO describes the power of circumpolar vortex [40], and the NAO index expresses the intensity of westerly airflow from the North Atlantic to the Atlantic European sector [53]. Their positive (negative) phase corresponds to the strengthening (weakening) of westerly circulation and prevailing of mild maritime (cold) airflow over the northern Europe, particularly during wintertime (e.g., $[20,54,55])$. Over Eurasia, Thompson et al. and Wallace et al. [40, 51] showed temperature is more strongly connected to the AO than to the NAO. Serreze et al. [56] concluded that the NAO could be considered as a major component of the AO. Previous studies reported shift in both AO and NAO from the negative to the positive phase in the early 1970s (e.g., [54, 57, 58]). Wang et al. [59] also found statistically significant increasing trends in both $\mathrm{AO}$ (0.26 per decade) and NAO (0.20 per decade) during recent decades. 


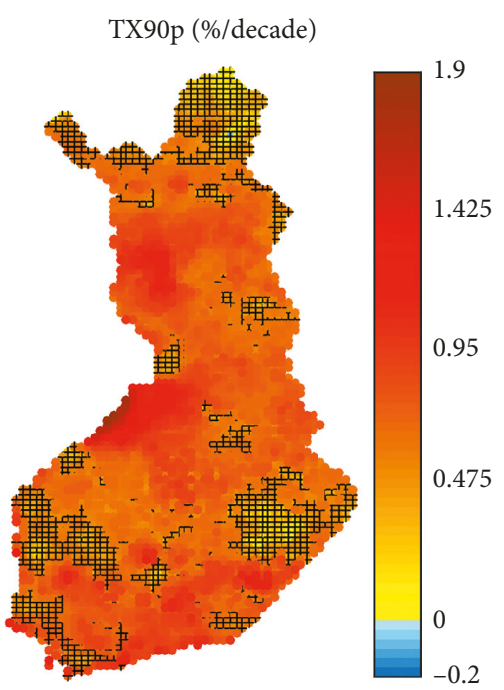

(a)

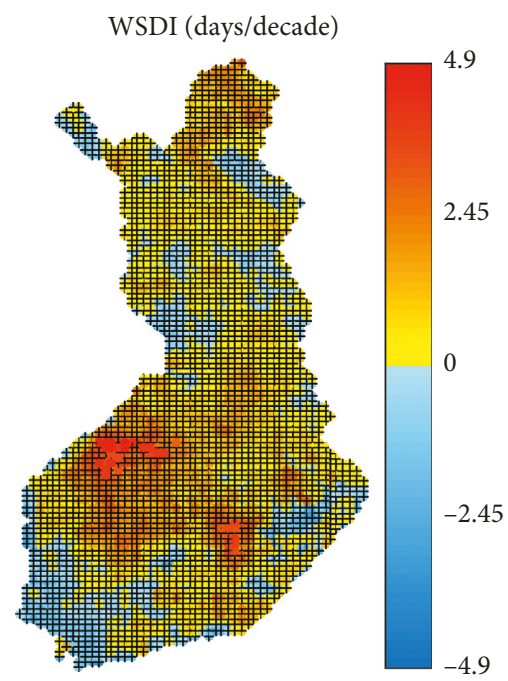

(d)

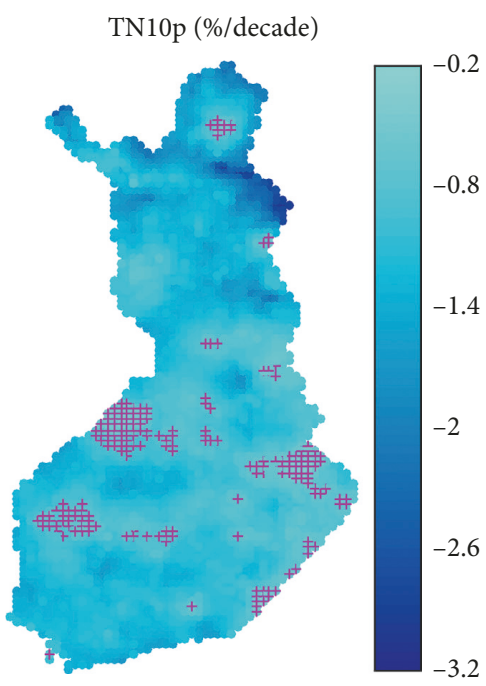

(b)

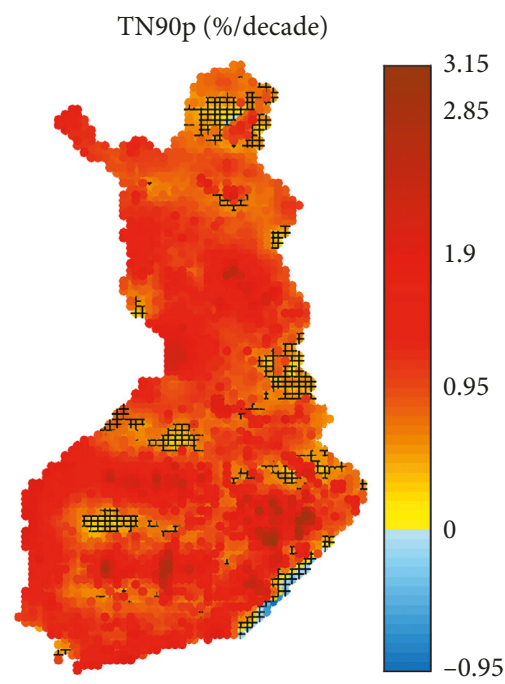

(c)

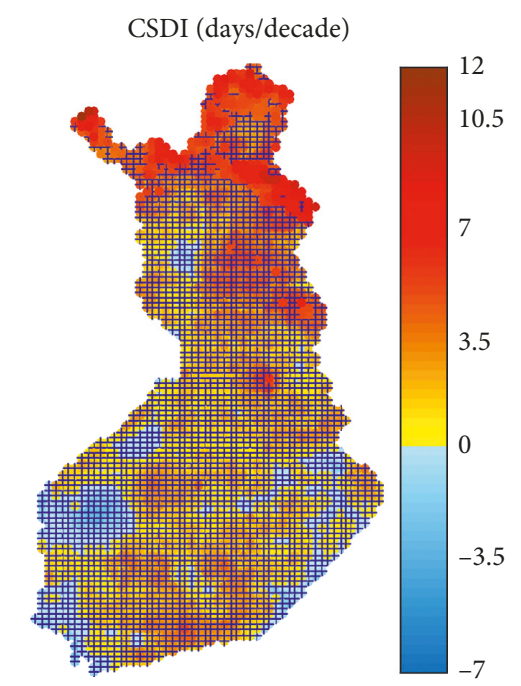

(e)

FIgURE 8: Spatial distribution maps of trends (/decade) in (a) TX90p, (b) TN10p, (c) TN90p, (d) WSDI, and (e) CSDI in Finland during 1961-2011. The stippling indicates areas where the trends are statistically insignificant $(p>0.05)$.

Strengthening of westerly circulation, such increases in AO, and NAO indices are generally responsible for recent winter temperature warming and consequently increases in the cold temperature extremes over the northern Europe.

This study found that EA/WR pattern negatively affected variations in DTR largely over the southern, eastern, and western Finland. Irannezhad et al. [25] concluded that the EA/WR pattern significantly influenced temperature in Finland during all seasons except summer. This NHTP (EA/WR) describes the meridional circulation for Finland that generally declines with the strengthening of westerly airflow. The positive EA/WR value is accompanied by the anomalous northerly and northwesterly airflow, while its negative value corresponds to the anomalous southerly and southeasterly circulation. Hence, the positive EA/WR phase associated with cold temperature in large parts of western Russia, northeast Africa, and the Arctic area, while warm temperature in east Asia (e.g., [38, 42]). Besides, observed significant increasing trend in EA/WR pattern during recent decade [60] can play a critical role in the climate variability over northern Europe throughout a year, which has received little attention in research communities.

WP pattern was the most influential NHTP for ETR variability mostly in the northern, southern, and eastern Finland. For this NHTP (WP), the positive phase results in warmer than normal climate at midlatitudes of the western North Pacific during summer and winter but colder climate in the east of Siberia in all seasons [51]. Irannezhad et al. [25] reported that the positive WP is usually associated with anomalous northerly airflow over Finland, causing negative temperature anomalies in the country during spring. However, the colder climate in the east of Siberia during the negative phase of the WP pattern seems to play a role in spring temperature variability in Finland, but the mechanisms through which this is identified remain to be determined. 


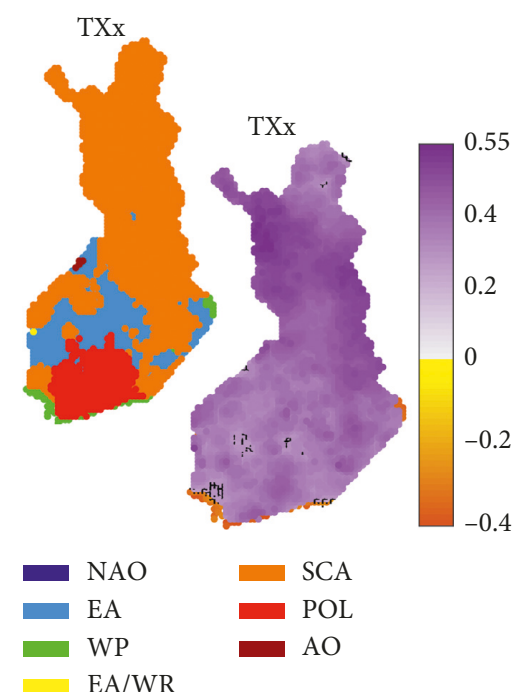

(a)

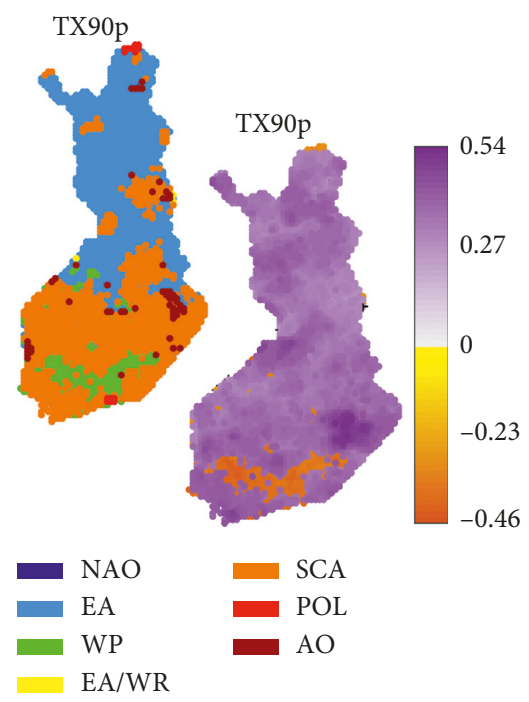

(d)

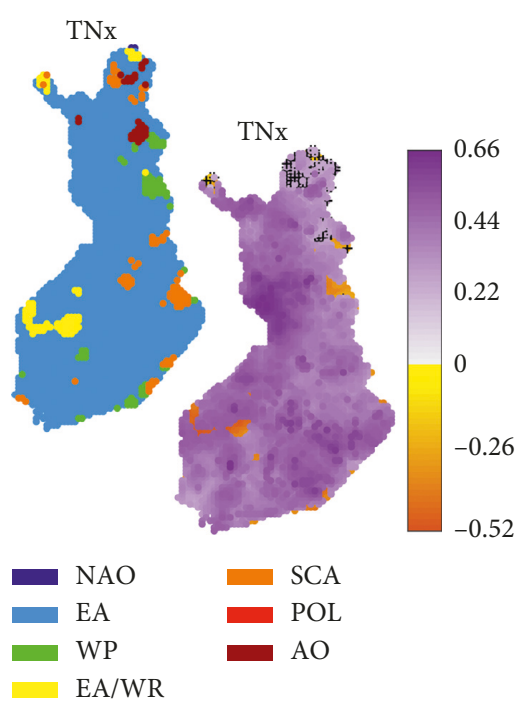

(b)

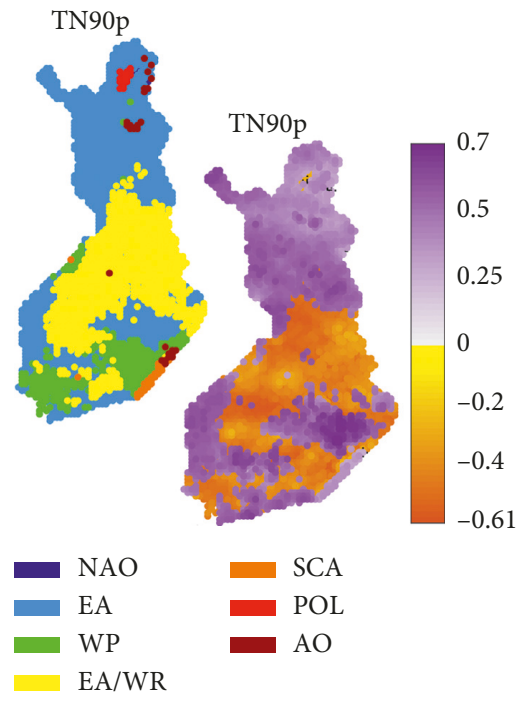

(e)

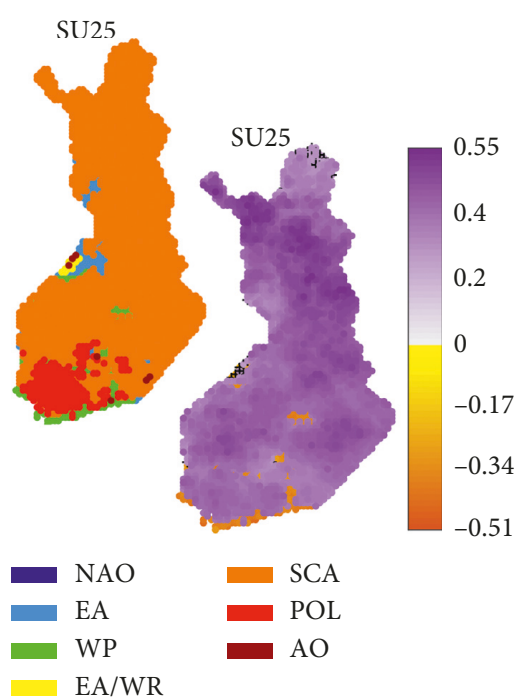

(c)

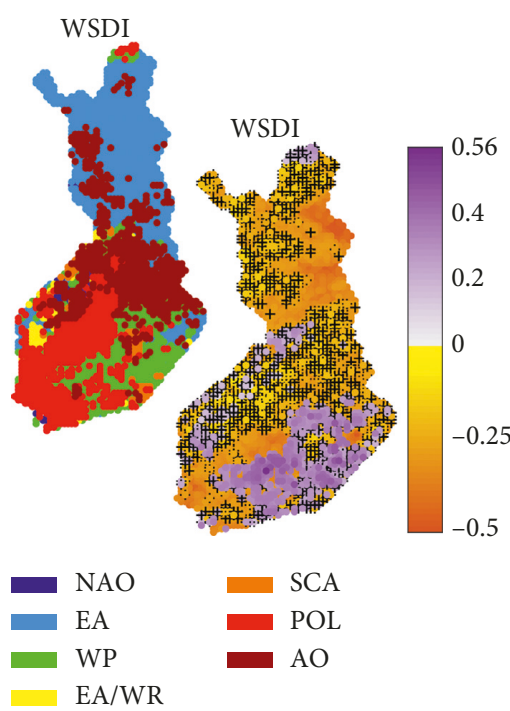

(f)

FIgURE 9: Spatial distribution maps of most influential NHTP (left) and its corresponding Spearman rank correlation (right) for warm extreme temperature indices including (a) TXx, (b) TNx, (c) SU25, (d) TX90p, (e) TN90p, and (f) WSDI in Finland during 1961-2011. The stippling indicates areas where the correlations are statistically insignificant $(p>0.05)$.

\section{Conclusions}

The present study evaluated the impacts of seven wellknown large-scale atmospheric circulation patterns, often referred to as Northern Hemisphere teleconnection patterns (NHTPs), on temperature statistics in Finland with a focus on extreme events in recent decades. Using daily gridded maximum and minimum temperature time series across Finland for the period 1961-2011, variations and trends in the fifteen temperature indices recommended by the ETCCDI were evaluated. The connections of these indices to the seven NHTPs were also identified. Major conclusions are drawn as follows:

(1) Significant increases in extreme temperatures were mainly revealed by warming trends in the TNx, TNn, and TXn indices. Different rates of the increasing trends in warm and cold extreme temperatures principally caused both diurnal (DTR) and extreme (ETR) temperature ranges to decline over the southwest and north of Finland. In general, all extreme temperature warming trends were associated with significant increases in the mean temperature over the country. However, warming trends in extreme temperatures were largely attributed to increases in cold temperature extremes rather than in warm temperature extremes.

(2) Significant increasing trends were determined in the numbers of warm days and nights, but the number of cold days and nights showed significant decreasing trends. Both the numbers of frost and icing days have 


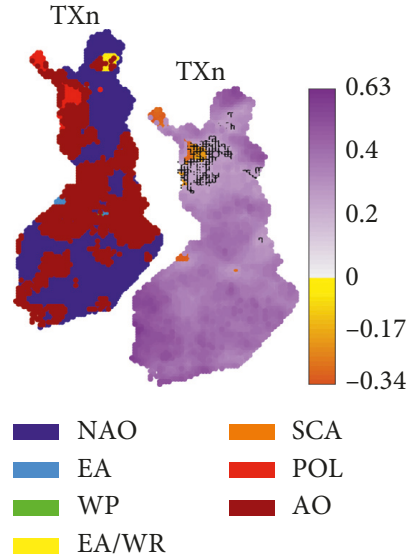

(a)

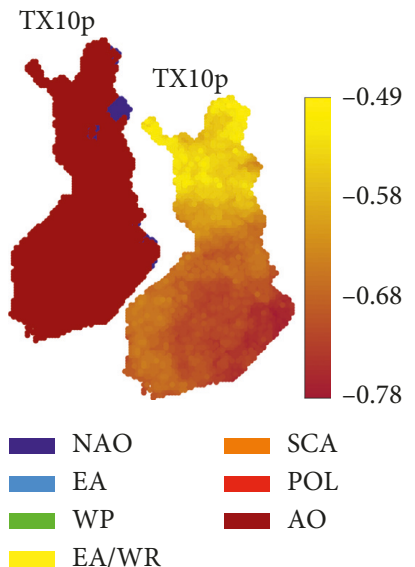

(e)
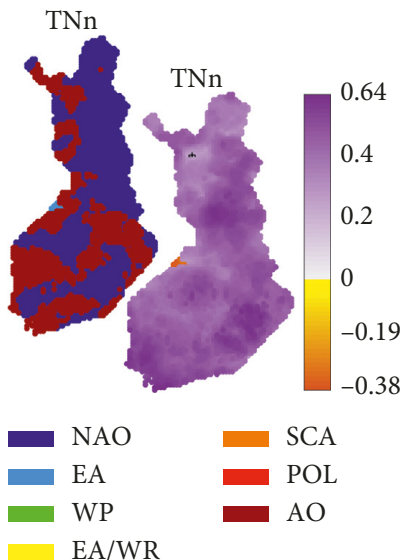

(b)

TN10p
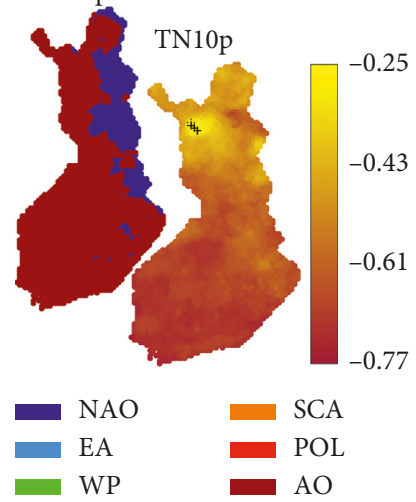

EA/WR

(f)

EA/WR
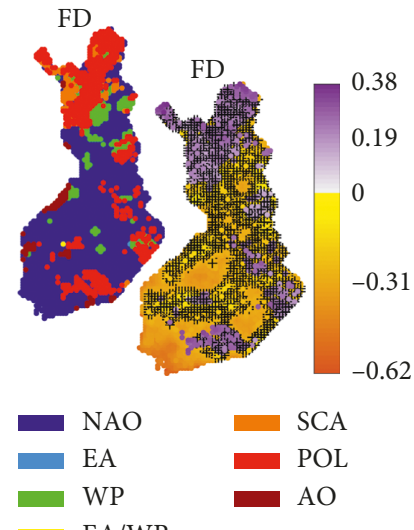

(c)

(d)

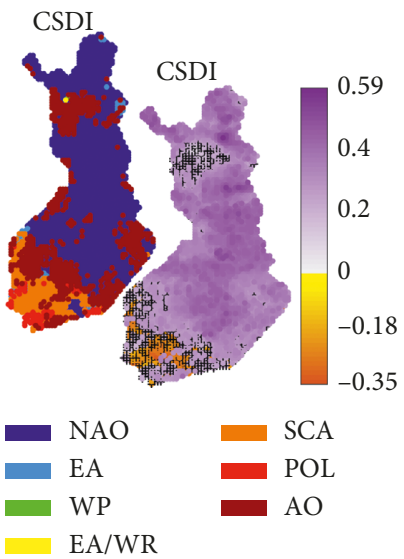

(g)

Figure 10: Spatial distribution maps of most influential NHTP (left) and its corresponding Spearman rank correlation (right) for cold temperature extreme indices including (a) TXn, (b) TNn, (c) FD, (d) ID, (e) TX10p, (f) TN10p, and (g) CSDI in Finland during 1961-2011. The stippling indicates areas where the correlations are statistically insignificant $(p>0.05)$.

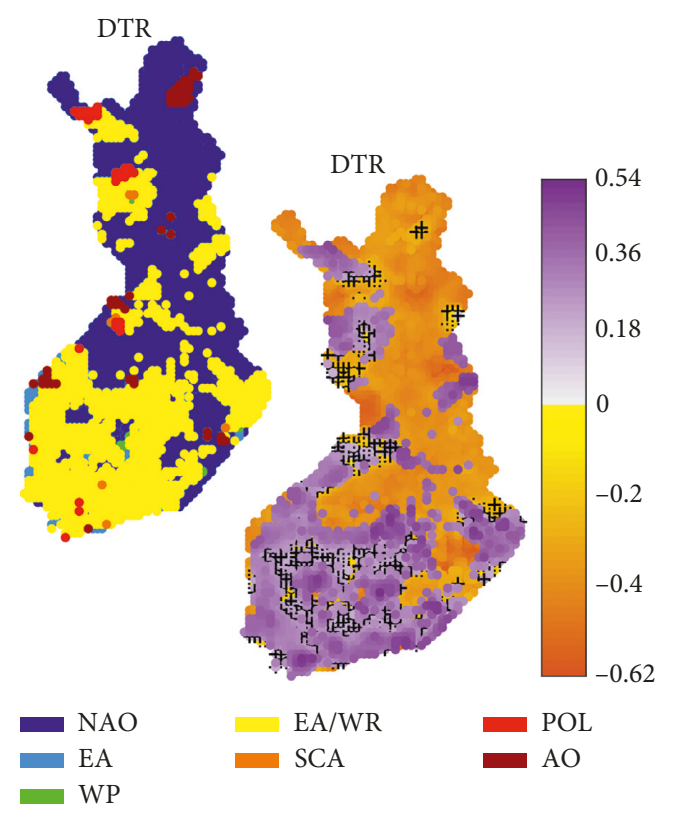

(a)

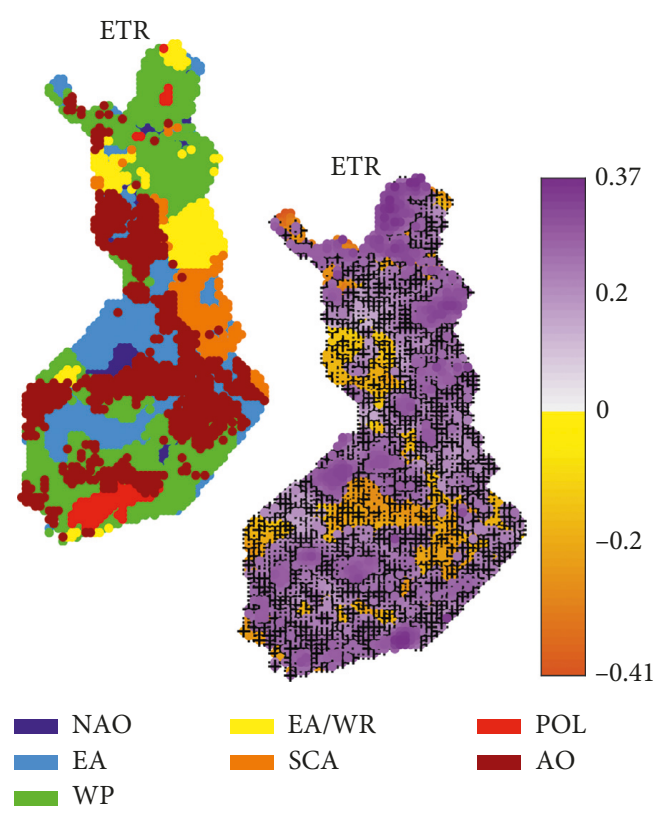

(b)

FIGURE 11: Spatial distribution maps of most influential NHTP (left) and its corresponding Spearman rank correlation (right) for (a) DTR and (b) ETR in Finland during 1961-2011. The stippling indicates areas where the correlations are statistically insignificant $(p>0.05)$. 
also decreased. Hence, warm temperature extreme events have become more frequent in Finland in recent decades, while the opposite occurred for cold temperature extreme events.

(3) For the whole country, both warm and cold spells showed no clear changes. Similarly, spatial trend analysis determined no significant changes in warm spells over different parts of Finland. In contrast, lengthening in cold spells has been observed over the upper areas of the northern Finland, which indicates the nonlinearity of the climate dynamics and demonstrates the complexity of extreme climate events.

(4) Temperature extremes over Finland were influenced by a number of NHTPs such as the EA, SCA, AO, $\mathrm{WP}$, and POL patterns. In general, warm temperature extremes were associated with the EA and SCA patterns, while cold temperature extremes with the $\mathrm{AO}$ and NAO patterns.

\section{Data Availability}

The data used to support the findings of this study are available from the corresponding author upon request.

\section{Conflicts of Interest}

The authors declare that they have no conflicts of interest.

\section{Acknowledgments}

The research presented in this paper was financially supported by Maa-Ja Vesitekniikan Tuki R.Y. and the Finnish Cultural Foundation. The authors gratefully thank the CSC-IT Centre for Science Ltd. for providing gridded daily minimum and maximum temperature time series for Finland and the Climate Prediction Centre (CPC) at the National Oceanic and Atmospheric Administration (NOAA) of the USA for making the standardized monthly values of ACPs accessible online.

\section{References}

[1] A. Ahmadalipour, H. Moradkhani, and M. Svoboda, "Centennial drought outlook over the CONUS using NASA-NEX downscaled climate ensemble," International Journal of Climatology, vol. 35, no. 5, pp. 2477-2491, 2016.

[2] D. Chen, A. Walther, A. Moberg, P. D. Jones, J. Jacobeit, and D. Lister, European Trend Atlas of Extreme Temperature and Precipitation, Springer, Dordrecht, Netherlands, 2015.

[3] S. Christoph and J. Gerd, "Hot news from summer 2003," Nature, vol. 432, pp. 559-560, 2004.

[4] U. S. De, R. K. Dube, and G. S. Prakasa Rao, "Extreme weather events over India in the last 100 years," Journal of Indian Geophysical Union, vol. 9, no. 3, pp. 173-187, 2005.

[5] IPCC, Managing the Risks of Extreme Events and Disasters to Advance Climate Change Adaptation: A Special Report of Working Groups I and II of the Intergovernmental Panel on Climate Change, Cambridge University Press, Cambridge, UK, 2012.
[6] L. V. Alexander, X. Zhang, T. C. Peterson et al., "Global observed changes in daily climate extremes of temperature and precipitation," Journal of Geophysical Research, vol. 111, no. D5, article D05109, 2006.

[7] M. G. Donat, L. V. Alexander, H. Yang et al., "Updated analyses of temperature and precipitation extreme indices since the beginning of the twentieth century, the HadEx2 dataset," Journal of Geophysical Research: Atmospheres, vol. 118, no. 5, pp. 2098-2118, 2013.

[8] P. Frich, L. V. Alexander, P. Della-Marta et al., "Observed coherent changes in climatic extremes during the second half of the 20th Century," Climate Research, vol. 19, pp. 193-212, 2002.

[9] A. M. G. Klein Tank, T. C. Peterson, D. A. Quadir et al., "Changes in daily temperature and precipitation extremes in Central and South Asia," Journal of Geophysical Research, vol. 111, no. D16, article D16105, 2006.

[10] L. A. Vincent and E. Mekis, "Changes in daily and extreme temperature and precipitation indices for Canada over the twentieth century," Atmosphere-Ocean, vol. 44, no. 2, pp. 177-193, 2006.

[11] EEA, "Climate change, impacts and vulnerability in Europe 2012-an indicator based report," European Environment Agency Report No. 12/2012, 2012, ISSN 1725-9177.

[12] A. M. Araghi, M. Mousavi-Baygi, and J. Adamowski, "Detection of trends in days with extreme temperatures in Iran from 1961 to 2010," Theoretical and Applied Climatology, vol. 125, no. 1, pp. 213-225, 2016.

[13] M. I. P. de Lima, F. E. Santo, A. M. Ramos, and J. L. M. P. de Lima, "Recent changes in daily precipitation and surface air temperature extremes in mainland Portugal, in the period 1941-2007," Atmospheric Research, vol. 127, pp. 195209, 2013.

[14] G. Fioravanti, E. Piervitali, and F. Desiato, "Recent changes of temperature extremes over Italy: an index-based analysis," Atmospheric Research, vol. 123, no. 3-4, pp. 473-486, 2016.

[15] A. Moberg, P. D. Jones, D. Lister et al., "Indices for daily temperature and precipitation extremes in Europe analyzed for the period 1901-2000," Journal of Geophysical Research, vol. 111, no. D22, article D22106, 2006.

[16] P. A. O'Gorman and T. Schneider, "The physical basis for increases in precipitation extremes in simulations of 21stcentury climate change," Proceedings of the National Academy of Sciences, vol. 106, no. 35, pp. 14773-14777, 2009.

[17] IPCC, Climate Change 2013: the Physical Science Basis: Working Group I Contribution to the Intergovernmental Panel on Climate Change Fifth Assessment Report (AR5)-Changes to the Underlying Scientific/Technical Assessment, Cambridge University Press, Cambridge, UK, 2013.

[18] M. H. Glantz, R. W. Katz, and N. Nicholls, Teleconnections Linking Worldwide Climate Anomalies: Scientific Basis and Societal Impact, Cambridge University Press, New York, NY, USA, 2009.

[19] A. Hoy, M. Sepp, and J. Matschullat, "Large-scale atmospheric circulation forms and their impact on air temperature in Europe and northern Asia," Theoretical and Applied Climatology, vol. 113, no. 3-4, pp. 643-658, 2013.

[20] A. Omstedt, C. Pettersen, J. Rodhe, and P. Winsor, "Baltic Sea climate: $200 \mathrm{yr}$ of data on air temperature, sea level variation, ice cover, and atmospheric circulation," Climate Research, vol. 25, pp. 205-216, 2004.

[21] R. M. Trigo, T. J. Osborn, and J. M. Corte-Real, “The North Atlantic Oscillation influence on Europe: climate impacts and 
associated physical mechanisms," Climate Research, vol. 20, pp. 9-17, 2002.

[22] S. Filahi, M. Tanarhte, L. Mouhir, M. El Morhit, and Y. Tramblay, "Trends in indices of daily temperature and precipitations extremes in Morocco," Theoretical and Applied Climatology, vol. 124, no. 3-4, pp. 959-972, 2016.

[23] S. Malinovic-Milicevic, M. M. Radovanovic, G. Stanojevic, and B. Milpvanovic, "Recent changes in Serbian climate extreme indices from 1961-2011," Theoretical and Applied Climatology, vol. 124, no. 3-4, pp. 1089-1098, 2016.

[24] W. Sun, X. Mu, X. Song, D. Wu, A. Cheng, and B. Qiu, "Changes in extreme temperature and precipitation events in the Loess Plateau (China) during 1960-2013 under global warming," Atmospheric Research, vol. 168, pp. 33-48, 2016.

[25] M. Irannezhad, D. Chen, and B. Kløve, "Interannual variations and trends in surface air temperature in Finland in relation to atmospheric circulation patterns, 1961-2011," International Journal of Climatology, vol. 35, no. 10, pp. 3078-3092, 2015.

[26] M. Tikkanen, The Physical Geography of Fennoscandia, M. Seppälä, Ed., Oxford University Press, Oxford, UK, 2005.

[27] D. Chen and H. W. Chen, "Using the Köppen classification to quantify climate variation and change: an example for 19012010," Environmental Development, vol. 6, pp. 69-79, 2013.

[28] H. Henttonen, Kriging in Interpolating July Mean Temperatures and Precipitation Sums. Reports from the Department of Statistics, University of Jyvaskyla, Jyvaskyla, Finland, 1991.

[29] B. D. Ripley, Spatial Statistic, Wiley, New York, NY, USA, 1981.

[30] H. Tietäväinen, H. Tuomenvirta, and A. Venäläinen, “Annual and seasonal mean temperatures in Finland during the last 160 years based on gridded temperature data," International Journal of Climatology, vol. 30, no. 15, pp. 2247-2256, 2010.

[31] H. Tuomenvirta, "Homogeneity adjustments of temperature and precipitation series-Finnish and Nordic data," International Journal of Climatology, vol. 21, no. 4, pp. 495-506, 2001.

[32] H. Tuomenvirta, Reliable Estimation of Climatic Variations in Finland, Finnish Meteorological Institute Contributions, Helsinki, Finland, 2004.

[33] A. Venäläinen, H. Tuomenvirta, P. Pirinen, and A. Drebs, “A basic Finnish climate data set 1961-2000-description and illustrations," Reports No. 2005:5, Finnish Metrological Institute, Helsinki, Finland, 2005.

[34] J. Aalto, P. Pirinen, J. Heikkinen, and A. Venäläinen, “Spatial interpolation of monthly climate data for Finland: comparing the performance of kriging and generalized additive models," Theoretical and Applied Climatology, vol. 112, no. 1-2, pp. 99-111, 2013.

[35] M. Irannezhad and B. Kløve, "Do atmospheric teleconnection patterns explain variations and trends in thermal growing season parameters in Finland?," International Journal of Climatology, vol. 35, no. 15, pp. 4619-4630, 2015.

[36] Y. Gao, T. Markkanen, T. Thum et al., "Assessing various drought indicators in representing summer drought in boreal forests in Finland," Hydrology and Earth System Sciences, vol. 20, no. 1, pp. 175-191, 2016.

[37] X. Zhang, L. Alexander, G. C. Hergel et al., "Indices for monitoring changes in extremes based on daily temperature and precipitation data," Wiley Interdisciplinary Reviews: Climate Change, vol. 2, no. 6, pp. 851-870, 2011.

[38] A. G. Barnston and R. E. Livezey, "Classification, seasonality and persistence of low-frequency atmospheric circulation patterns," Monthly Weather Review, vol. 115, no. 6, pp. 1083-1126, 1987.

[39] M. Irannezhad, H. Marttila, and B. Kløve, "Long-term variations and trends in precipitation in Finland," International Journal of Climatology, vol. 34, no. 10, pp. 3139-3153, 2014.

[40] D. W. J. Thompson and J. M. Wallace, "The Arctic Oscillation signature in the wintertime geopotential height and temperature fields," Geophysical Research Letters, vol. 25, no. 9, pp. 1297-1300, 1998.

[41] CPC, http://www.cpc.ncep.noaa.gov/data/teledoc/telecontents. shtml, 2011.

[42] Y. K. Lim and H. D. Kim, "Impact of the dominant large-scale teleconnections on winter temperature variability over East Asia," Journal of Geophysical Research: Atmospheres, vol. 118, no. 14, pp. 7835-7848, 2013.

[43] C. Bueh and H. Nakamura, "Scandinavian pattern and its climatic impact," Quarterly Journal of the Royal Meteorological Society, vol. 133, no. 627, pp. 2117-2131, 2007.

[44] M. G. Kendall, Rank Correlation Methods, Griffin, London, UK, 1975.

[45] H. B. Mann, "Nonparametric tests against trend," Econometrica, vol. 13, no. 3, pp. 245-259, 1945.

[46] S. Yue, P. Pilon, R. Phinney, and G. Cavadias, "The influence of autocorrelation on the ability to detect trend in hydrological series," Hydrological Processes, vol. 16, no. 9, pp. 1807-1829, 2002.

[47] E. Park and Y. J. Lee, "Estimates of standard deviation of Spearman's rank correlation coefficients with dependent observations," Communications in Statistics-Simulation and Computation, vol. 30, no. 1, pp. 129-142, 2001.

[48] P. K. Sen, "Estimates of the regression coefficient based on Kendall's tau," International Journal of Statistics \& Economics, vol. 63, no. 324, pp. 1379-1389, 1968.

[49] D. R. Helsel and R. M. Hirsch, Statistical Methods in Water Resources, Studies in Environmental Science, Amsterdam, Netherlands, 1992.

[50] S. Mikkonen, M. Laine, H. M. Mäkelä et al., "Trends in the average temperature in Finland, 1847-2013," Stochastic Environmental Research and Risk Assessment, vol. 29, no. 6, pp. 1521-1529, 2015.

[51] J. M. Wallace and D. S. Gutzler, "Teleconnections in the geopotential height field during the Northern Hemisphere winter," Monthly Weather Review, vol. 109, no. 4, pp. 784-812, 1981.

[52] F. Panagiotopoulos, M. Shahgedanova, and D. B. Stephenson, "A review of Northern Hemisphere winter-time teleconnection patterns," Journal of Physics, vol. 12, no. 10, pp. 27-47, 2002.

[53] J. W. Hurrell, "Decadal trends in the North Atlantic Oscillation: regional temperatures and precipitation," Science, vol. 269, no. 5224, pp. 676-679, 1995.

[54] A. K. Gormsen, A. Hense, T. B. Toldam-Andersen, and P. Braun, "Large-scale climate variability and its effects on mean temperature and flowering time of Prunus and Betula in Denmark," Theoretical and Applied Climatology, vol. 82, no. 1-2, pp. 41-50, 2005.

[55] J. Jaagus, "Climatic changes in Estonia during the second half of the 20th century in relationship with changes in large-scale atmospheric circulation," Theoretical and Applied Climatology, vol. 83, no. 1-4, pp. 77-88, 2006.

[56] M. C. Serreze, J. E. Walsh, F. S. Chapin et al., "Observational evidence of recent change in the northern high-latitude environment," Climatic Change, vol. 46, no. 1-2, pp. 159-207, 2000. 
[57] A. Bukantis and G. Bartkeviciene, "Thermal effects of the North Atlantic Oscillation on the cold period of the year in Lithuania," Climate Research, vol. 28, pp. 221-228, 2005.

[58] S. Järvenoja, Arctic Oscillation and its impact on Finland's climate: XXII Geophysical Days, May 19-20, Helsinki, 2005.

[59] D. Wang, C. Wang, X. Yang, and J. Lu, "Winter Northern Hemisphere surface air temperature variability associated with the Arctic Oscillation and North Atlantic Oscillation," Geophysical Research Letters, vol. 32, article L16706, 2005.

[60] S. O. Krichak, P. Kishcha, and P. Alpert, "Decadal trends in of main Eurasian oscillations and the Mediterranean precipitation," Theoretical and Applied Climatology, vol. 72, no. 3-4, pp. 209-220, 2002. 

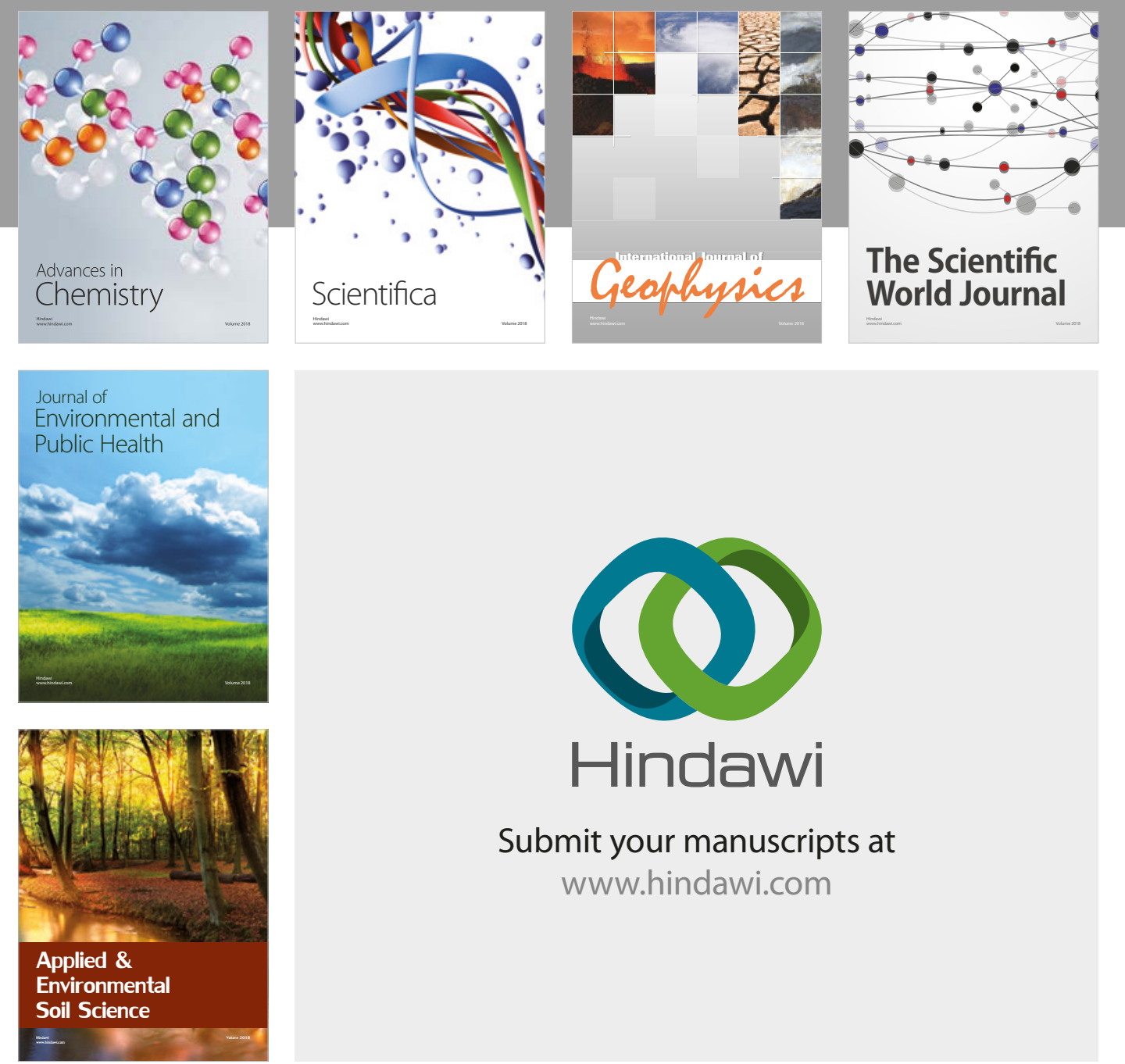

The Scientific

\section{World Journal}
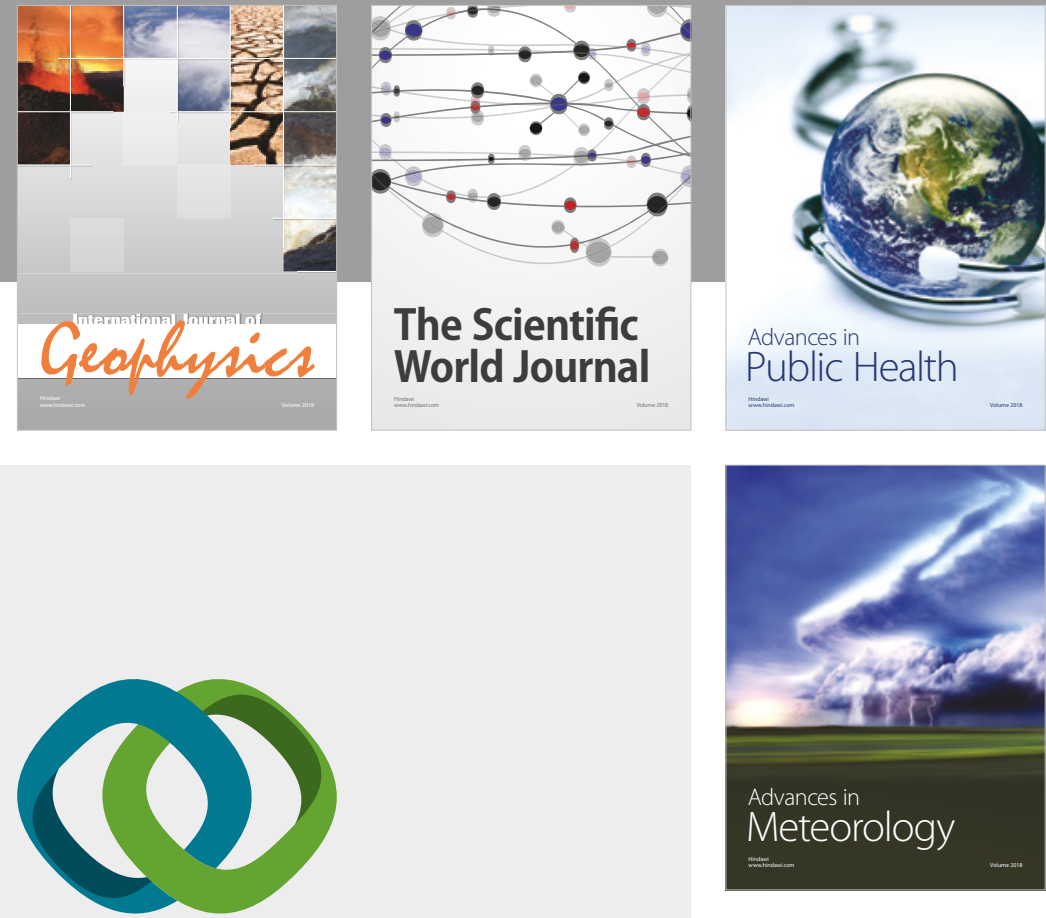

Advan

Public Health

\section{Hindawi}

Submit your manuscripts at

www.hindawi.com
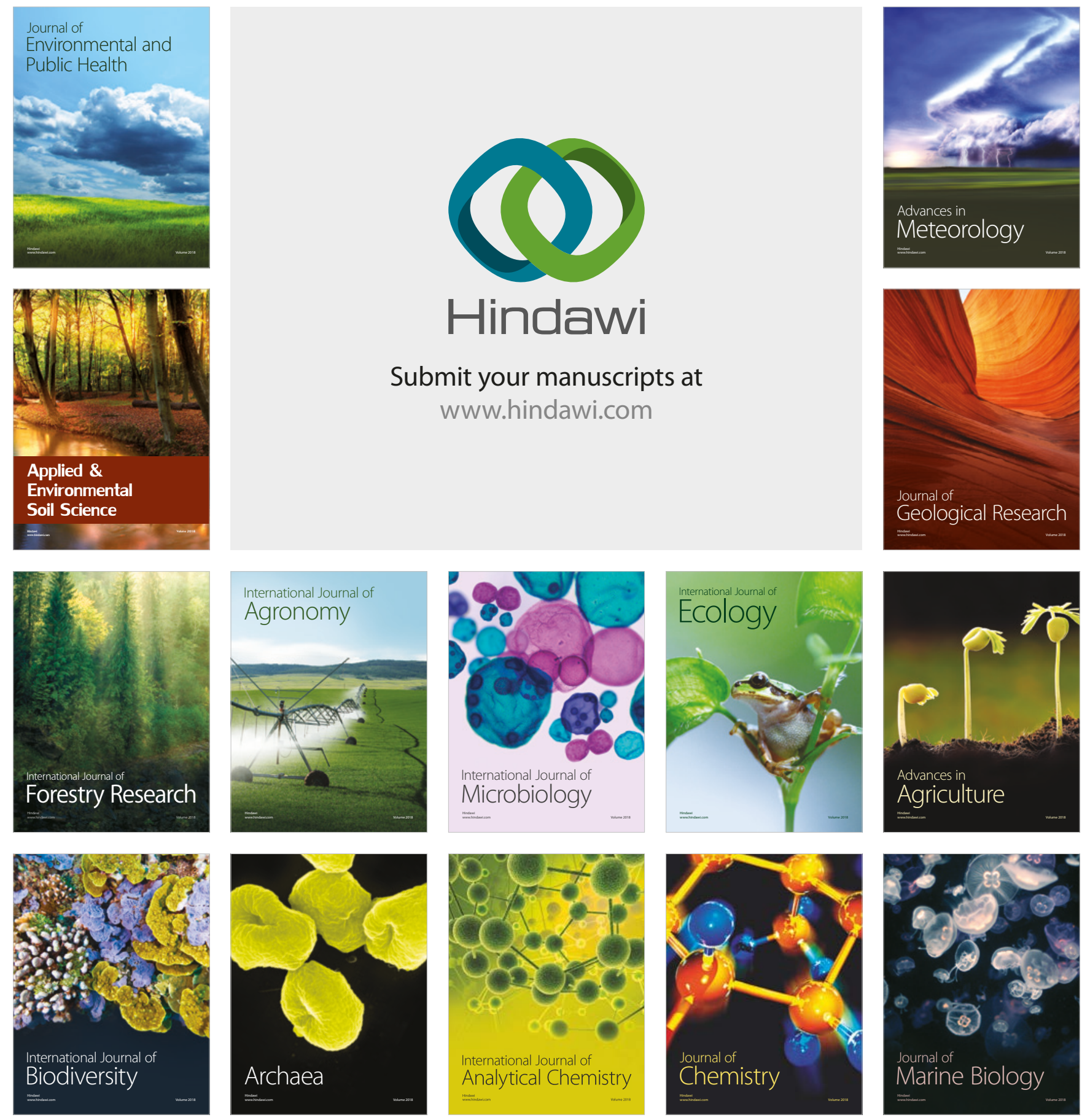